\title{
Physical Simulations of Cavity Closure in a Creeping Material
}

Herbert J. Sutherland, Dale S. Preece

\author{
preparted by \\ Sandia National Laboratories

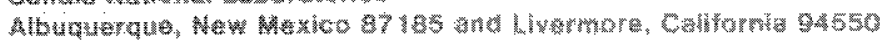

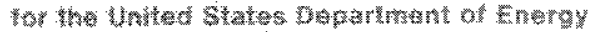 \\ under Conturat bt-Aco4-760poorag
}


Issued by Sandia National Lahoratories, operated for the United States Department of Energy by Sandia Corporation.

NOTICE: This report was prepared as an account of work sponsored by an agency of the United States Government. Neither the United States Government nor any agency thereof, nor any of their employees, nor any of their contractors, subcontractors, or their employees, makes any warranty, express or implied, or assumes any legal liability or responsibility for the accuracy, completeness, or usefulness of any information, apparatus, product, or process disclosed, or represents that its use would not infringe privately owned rights. Reference herein to any specific commercial product, process, or service by trade name, trademark, manufacturer, or otherwise, does not necessarily constitute or imply its endorsement, recommendation. or favoring by the United States Government, any agency thereof or any of their contractors or subcontractors. The views and opinions erpreseed heretheir contractors or subcontractors. The views and opinions expressed herein do not necessarily state or reflect those of the United States Government, any agency thereof or any of their contractors or subcontractors.

Printed in the United States of America Available from

National Technical Information Service U.S. Department of Commerce

5285 Port Royal Rosd

Springfield, VA 22161

NTIS price codes

Printed copy: A04

Microfiche copy: A01 
Distribution

Category UC-94E

SANDB5-0505

Unlimited Release

Printed September 1985

\section{PHYSICAL SIMULATIONS OF CAVITY CLOSURE IN A CREEPING MATERIAL}

by

Herbert J. Sutherland

and

Dale S. Preece

Sandia National Laboratories

Albuquerque, NM 87185

\section{ABSTRACT}

The finite element method has been used extensively to predict the creep closure of underground petroleun storage cavities in rock salt. Even though the numerical modeling requires many simplifying assumptions, the predictions have generally correlated with field data from instrumented wellheads; however, the field data are rather 1 imited. To gain an insight into the behavior of three-dimensional arrays of cavities and to obtain a larger data base for the verification of analytical simulations of creep closure, a series of six centrifuge simulation experiments were performed using a cylindrical block of modeling clay, a creeping material. Three of the simulations were conducted with single, centerline cavities, and three were conducted with a symmetric array of three cavities surrounding a central cavity. The models were subjected to body force loading using a centrifuge. For the single cavity experiments, the models were tested at accelerations of 100,125 and $150 \mathrm{~g}$ 's for 2 hours. For the multi-cavity experiments, the simulations were conducted at $100 \mathrm{~g}$ 's for 3.25 hours. The results are analyzed using dimensional analyses. The analyses illustrate that the centrifuge simulations yield self-consistent simulations of the creep closure of fluid-filled cavities and that the interaction of threedimensional cavity layouts can be investigated using this technique. 
List of Tables... . . . . . . . . . . . . . . . . . . . . . . 5

List of Figures. . . . . . . . . . . . . . . . . . . . . . . 6

List of Appendices . . . . . . . . . . . . . . . . . . . . . . . . . . . . . 8

INTRODUCTION . . . . . . . . . . . . . . . . . . . . . . . . . . . . . . 9

MATERIAL PROPERTIES. . . . . . . . . . . . . . . . . . . . . . . . . . . 10

Material Description. . . . . . . . . . . . . . . . . . . . . . . . 10

Material Tests. . . . . . . . . . . . . . . . . . . . . . . . . 10

EXPERIMENTAL TECHNIQUES. . . . . . . . . . . . . . . . . . . . . . . . . 17

Specimen Fabrication. . . . . . . . . . . . . . . . . . . . . . . . 17

Test Fixtures... . . . . . . . . . . . . . . . . . . . 18

Centrifuge. . . . . . . . . . . . . . . . . . . . . . . . . . . . . 18

Single Cavity Experiments . . . . . . . . . . . . . . . . . . . . . 18

Multi-Cavity Experiments. . . . . . . . . . . . . . . . . . . . . . 21

Post Test Analysis. . . . . . . . . . . . . . . . . . . . . . . . 23

Digitizing. . . . . . . . . . . . . . . . . . . . . . . . . 23

Volume Calculation. . . . . . . . . . . . . . . . . . . . . . 32

Results. . . . . . . . . . . . . . . . . . . . . . . . 33

DIMENSIONAL ANALYSIS . . . . . . . . . . . . . . . . . . . . . . . . . . 36

Scaling Relation on Time. . . . . . . . . . . . . . . . . . . 36

Prototype Cavity. . . . . . . . . . . . . . . . . . . . . . . . . . 38

Homologous Times. . . . . . . . . . . . . . . . . . . . . . . . . . 40

Average Driving Stress Analysis . . . . . . . . . . . . . . . . . . 40

Remarks . . . . . . . . . . . . . . . . . . . . . 45

Discussion of Results. . . . . . . . . . . . . . . . . . . . . . . 45

CONCLUDING REMARKS . . . . . . . . . . . . . . . . . . . . . . . . . . . 47

ACKNOWLEDGMENTS . . . . . . . . . . . . . . . . . . . . . . . . . . 48 


\section{TABLES}

Page

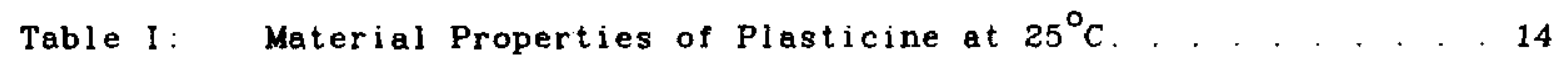

Table II: Final Cavity Volumes for Single Cavity Tests.

Test time 2 hours. . . . . . . . . . . . . . . . . . . . . . 34

Table III: Final Cavity Volumes for Multi-Cavity Tests. Test time 3.25

hours, $15 \mathrm{~min}$ at $100 \mathrm{G}$ 's.............. . . 35 


\section{FIGURES}

Figure 1: Typical Stress-Strain Curves for Plasticine. . . . . . . . . 12 a. Ivory Plasticine

b. Green Plasticine

c. Gray Plasticine

Figure 2: Yield Stress vs Strain Rate for Plasticine........ . . . 13

Figure 3: Equilibrium Stress vs Strain Rate for Plasticine...... 16

Figure 4: The Sandia CA-2 Centrifuge . . . . . . . . . . . . . . . . . . . . . 19

Figure 5: Schematic Diagram of the Single Cavity Experiments... . . 20

Figure 6: Schematic Diagram of the Multi-Cavity Experiments. . . . . . 22

Figure 7: Cross-Sectional Views of the Single Cavity Experiments . . 24

Figure 8: Cross-Sectional Views of the Multi-Cavity Experiments. . . . 25

Figure 9: Digitized Cross Section from Cavity SE100. Test time

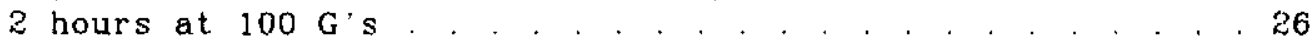

Figure 10: Digitized Cross Section from Cavity SE125. Test time

2 hours at $125 \mathrm{G}$ 's . . . . . . . . . . . . . . . . 27

Figure 11: Digitized Cross Section from Cavity SE150. Test time

2 hours at $150 \mathrm{G}$ 's. . . . . . . . . . . . . 28

Figure 12. Digitized Cross Section from Cavity ME3A. Test time

3.25 hours at $100 \mathrm{G}^{\prime} \mathrm{s}$. . . . . . . . . . . . . . 29

Figure 13: Digitized Cross Section from Cavity ME2A. Test time

3.25 hours at $100 \mathrm{G}^{\prime} \mathrm{s} . . .30$

Figure 14: Digitized Cross Section from Cavity ME1A. Test time 3.25 hours at $100 \mathrm{G}^{\prime} \mathrm{s}$. . . . . . . . . . . . . . . . 31

Figure 15: Constitutive Equations for Green Plasticine and

West Hackberry Domal Salt. . . . . . . . . . . . . . . . . 37

Figure 16: Cross Section of West Hackberry Cavern 11. . . . . . . . . . 39

Figure 17: Effect of a Reduced Flujd Head on the Measured Volume Loss . . . . . . . . . . . . . . . . 41 
Figure 18: Volume Loss Predictions Based on an Extrapolation of the West Hackberry Cavern 11 Data . . . . . . . . . . . . . . . 42

Figure 19: Average Driving Stress for Green Plasticine . . . . . . . . 44

Figure D-1: Axisymmetric Finite Element Model of Single Cavity

Experiments. . . . . . . . . . . . . . . . . . . . . . 62

Figure D-2: Comparison of Experimental and Finite Element Results. . . 63 


\section{APPENDICES}

Page

Appendix A:

Appendix $B$ :

Appendix $\mathrm{C}$ :

Appendix $\mathrm{D}$ :
Plasticine: Experimental Procedures . . . . . . . 50

Salt Plugs: Experimental Procedures . . . , . . . 54

FORTRAN Computer Program for Calculating

Volumes from Digitized Outlines. . . . . . . . . . 56

Finite Element Simulations of the Cavity

Creep Closure. . . . . . . . . . . . . . . . 61 
INTRODUCT ION

Finite element methods have been used extensively for several years to calculate the creep closure of Strategic Petroleum Reserve (SPR) storage cavities in rock salt. Two-dimensionel axisymetric finite element. calculations performed thus far required many simplifying assumptions to reduce the three-dimensional cavern arrays to the necessary two dimensions for the calculations. More recently, three-dimensional finite element calculations have been performed which accurately simulate actual arrays of caverns. Regardless of this improved capability in calculational techniques, inadequate field data have made it difficult to judge the agreement between computational predictions and actual behavior. In part, this deficiency in field data can be overcome through the use of physjcal simulations based on centrifuge techniques. Thus, to obtain an improved understanding of threedimensional effects, such as cavern spacing, and to add to the data base for calculational comparisons, a number of large physical models were tested using centrifuge techniques.

The centrifuge simulations discussed here examine the closure of fluid-filled cavities in a creeping material. Plasticine, or modeling clay, was used as the creeping material. The material was chosen for these experiments because it creeps at a much faster rate than salt and it can be characterized with a secondary creep formulation. Consequently, it gives a measurable cavity closure in a reasonable centrifuge test time. Through dimensional analysis, the plasticine simulations can be extrapolated to predict the long-term behavior of fluid storage caverns in rock salt.

This report begins with a discussion of the mechanical and creep properties of the plastlcine. The two simulation test series are then discussed. The first series consisted of single cavity simulations performed at three different accelerations. The second series consisted of multi-cavity simulations performed at a single g level but with varying cavity layouts. The results of the first series are used as a baseline data base for comparison to the results produced by the more complex second serles. Detailed discussions of the experimental results and comparison to numerical calculations close the report. 
MATERIAL PROPERTIES

Plasticine has been used by several investigators to simulate the behavior of creeping materials; e.g., see Ramberg's discussion of modeling materials for centrifuge simulations [1]. A detailed description of plasticine's mechanical behavior is given by McClay [2] and Crandall, et. al. [3]. As discussed by McClay, the creep behavior of plasticine can be described by a constitutive model using a power law in stress. The constitutive constants for this formulation change with material manufacturer, grade, and color. Through careful material control and characterization, plasticine becomes a very good physical model material for creep simulations.

Material Description

As the original plasticine material tested by McClay was no longer available, a material had to be characterized. The trade name of the material tested here is "Plastalina, Leisure Clay," manufactured by Leisurecrafts Co.; Los Angeles, CA.

The material was manufactured in several premixed colors: ivory, green, gray and black. However, other colors could be obtained by mixing Tempera pigment ("Fresco Powder Tempera", Rich Art Color Co., Ine., Lodi, NJ) wath the ivory plasticine. For our work, pigment was added at a ratio of $5.0 \mathrm{gm}$ of pigment to $100 \mathrm{gm}$ of plasticine. The additional colors tested here were red and blue.

Material Tests

The density of the plasticine was measured using the standard water displacement technique. The density for the ivory, green, gray and black plasticine was found to be $1.71 \mathrm{gm} / \mathrm{cm}^{3}$ with a standard deviation of $0.004 \mathrm{gm} / \mathrm{cm}^{3}$. With the red or blue pigment added to the ivory, the density increased to $1.75 \mathrm{gm} / \mathrm{cm}^{3}$ with a standard deviation of $0.009 \mathrm{gm} / \mathrm{cm}^{3}$. 
The plasticine was tested in uni-axial compression at several constant strain rates. The test specimens were $25.4 \mathrm{~mm}$ (1 in) in diameter and $50.8 \mathrm{~mm}$ (2 in) in length. The tests were conducted at strain rates varying from $1 \times 10^{-3} / \mathrm{s}$ to $3 \times 10^{-6} / \mathrm{s}$. The temperature of the sample was controlled at $25^{\circ} \mathrm{C} \pm 0.5^{\circ} \mathrm{C}$.

A typical set of true stress and strain plots, from the tests of ivory, green and gray plasticine is shown in Figure 1. To obtain the true stress-strain curve, the raw data have been corrected for the change in cross section resulting from the finite deformation of the sample. The formula used for this correction is first order, as based on a constant volume; namely.

$$
\begin{aligned}
& S_{E}=F / A_{0} \\
& S_{T}=S_{E}(1-e)
\end{aligned}
$$

where $S_{E}$ is the engineering stress, $F$ is the force on the specimen, $A_{0}$ is its original area, $S_{T}$ is the true stress, and $e$ is the axial strain.

As can be seen in Figure 1, the one-dimensional (Young's) modulus of the plasticine does vary slightly with strain rate. However, as this variation is relatively small, we have chosen to report only the modulus for a strain rate of $10^{-4} / \mathrm{s}$ in our constitutive summary. Table $\mathrm{l}$.

As shown in Figure 1, the plasticine has a definite yield point (yield stress). These data were fit using a linear regression analysis to an exponential equation of the form:

$$
\dot{e}=K_{0} Y^{n}
$$

where $\dot{e}$ is the strain rate, $K_{0}$ is the leading coefficient, $Y$ is the yield stress, and $n$ is the stress exponent. The fits are shown in Figure 2

After the pronounced yield point, the plasticine flows at a nearly constant, but. lower stress. This lower stress is interpreted as an equilibrium stress and is equivalent to the constant stress of a creep test. Following the lead 


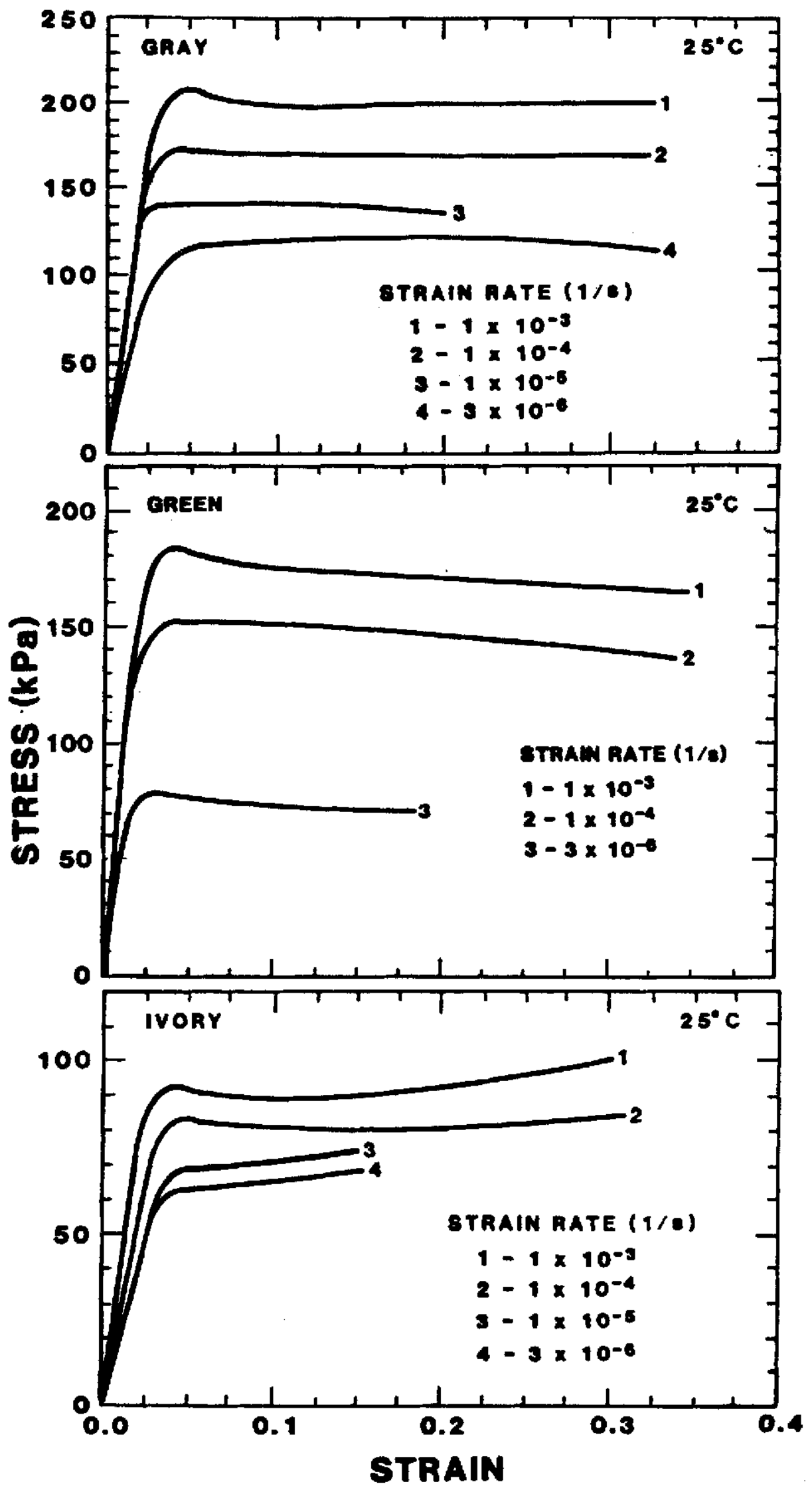

Figure 1: Typical Stress-Strain Curves for Plastacine 


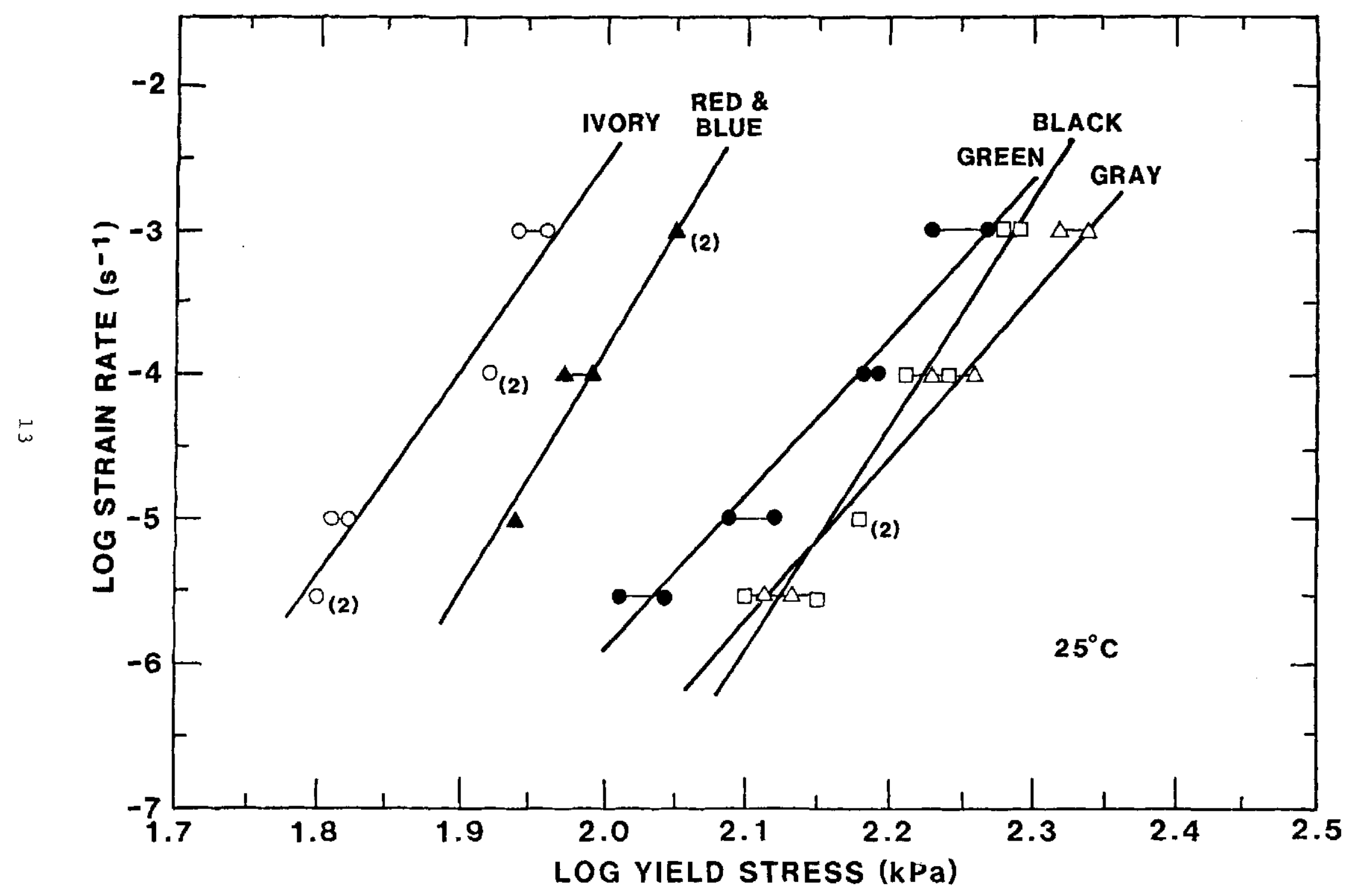

Figure 2: Yield Stress vs Strain Rate for Plasticine 
Table I

Material Properties of Plasticine at $25^{\circ} \mathrm{C}$

\begin{tabular}{|c|c|c|c|c|c|c|c|c|}
\hline \multirow{4}{*}{$\begin{array}{l}\text { Material } \\
\text { Description }\end{array}$} & \multicolumn{7}{|c|}{ Material Constants $[1,2]$} & \\
\hline & Density & \multirow{3}{*}{$\begin{array}{l}\text { Longl tudinal } \\
\text { Madulus [3] } \\
\text { kPa(psi) }\end{array}$} & \multicolumn{3}{|c|}{ Yield Stress Curve Fit [EQ 3] } & \multicolumn{3}{|c|}{ Creep Law Curve Fit [Eq.4] } \\
\hline & $\mathrm{gm} / \mathrm{cm}^{3}$ & & $\begin{array}{l}\text { Leading } \\
\text { Coefficient }\end{array}$ & Exponent & $\begin{array}{l}\text { Coefficient of } \\
\text { Determination }\end{array}$ & $\begin{array}{l}\text { Leeding } \\
\text { Coefficient }\end{array}$ & Exponent & $\begin{array}{l}\text { Coefficient of } \\
\text { Determination }\end{array}$ \\
\hline & & & $\mathrm{K}_{0}$ & $\mathbf{n}$ & $r$ & K & $\mathbf{n}$ & $r$ \\
\hline Ivory & 1.71 & $\begin{array}{r}2290 \\
(330)\end{array}$ & $\begin{array}{c}1.15 E-31 \\
(9.08 E-20)\end{array}$ & 14.2 & 0.93 & $\begin{array}{c}2.82 \mathrm{E}-52 \\
(1.45 \mathrm{E}-31)\end{array}$ & 24.7 & $0.95[4]$ \\
\hline Green & 1.71 & $\begin{array}{r}6830 \\
(990)\end{array}$ & $\begin{array}{c}2.32 \mathrm{E}-28 \\
(2.96 \mathrm{E}-19)\end{array}$ & 10.9 & 0.95 & $\begin{array}{c}3.8 \mathrm{BE}-26 \\
(1.19 \mathrm{E}-17)\end{array}$ & 10.1 & $0.99[5]$ \\
\hline Gray & 1.71 & $\begin{array}{r}6490 \\
(940)\end{array}$ & $\begin{array}{c}6.41 \mathrm{E}-30 \\
(1.67 \mathrm{E}-20)\end{array}$ & 11.2 & 0.99 & $\begin{array}{c}7.25 E-30 \\
(1.82 E-20)\end{array}$ & 11.2 & 0.99 \\
\hline Black & 1.71 & $\begin{array}{r}4880 \\
(710)\end{array}$ & $\begin{array}{c}1.028-38 \\
(6.28 E-26)\end{array}$ & 15.3 & 0.93 & $\begin{array}{c}4.04 E-36 \\
(2.74 E-24)\end{array}$ & 14.1 & 0.90 \\
\hline Red \& Blue $[6]$ & ] 1.75 & $\begin{array}{r}3500 \\
(510)\end{array}$ & $\begin{array}{c}5.84 E-38 \\
(5.88 E-24)\end{array}$ & 16.7 & 0.94 & $\begin{array}{c}2.43 E-35 \\
(1.64 E-22)\end{array}$ & 15.3 & 0.94 \\
\hline
\end{tabular}

NOTES :

1. Strain rate in $1 / \mathrm{s}$.

Stress in $\mathrm{kPa}$ (psi).

Young's modulus at $1 \mathrm{E}-4 / \mathrm{s}$ strain rate.

Exclude one $1 E-4 / s$ strain rate data point.

Exclude $1 E-4 / s$ strain rate data.

6. Standard ivory plasticine colored with tempra pigment 
of McClay [2], the constitutive equation relating equilibrium stress to strain rate is formulated in a power law of the form:

$$
\dot{e}=K\left(S_{T}\right)^{n}
$$

where $K$ is the leading coefficient, and $n$ is the power law exponent. This formulation implies a steady state strain rate and stress level. Using the flat portion of the true stress-strain plots of Figure 1 and a linear regression analysis, the data for the various materials were used to generate the fits shown in Figure 3 .

These constitutive data are summarized in Table I. 


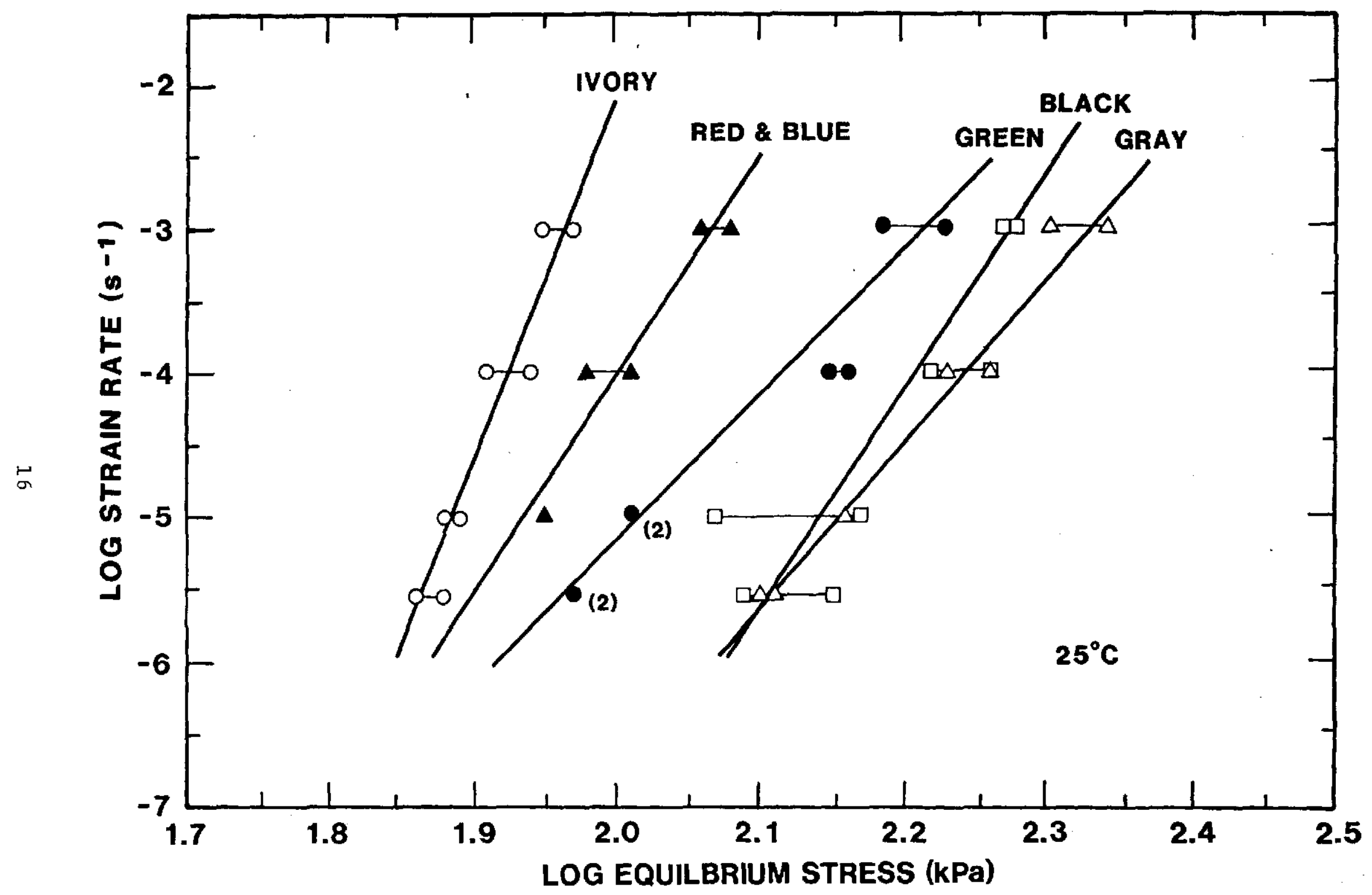

Figure 3: Equilibrium Stress vs Strain Rate for Plasticine 
EXPERIMENTAL TECHNIQUES

Specimen Fabrication

The experiments required large, uniform cylindrical blocks of plasticine. The procedures developed for the casting, machining and assembly of these blocks are listed in Appendix A and Appendix B. In general, a casting process was used to form the plasticine models, see Appendix A. First, the appropriate quantities of plasticine were melted and poured into the fixture used for the centrifuge experiment. Then, the blocks were parted, appropriate cavities and surfaces were cut, and the model was reassembled.

During the preparation of the plasticine test models, appropriate cylindrical cavities were machined into the block of plasticine. As plasticine is a creeping material, we felt, initially, that the cavity shapes could change during the period between machining and testing. To insure that this longterm material creep did not affect our results, the cavities were filled with rubber-coated salt plugs. The cavities were connected to the "surface" through plastic pipes or risers. The salt plugs were removed imnediately before testing using a spray of water, through the riser, to dissolve the plug. This "lost wax" processing technique is described in Appendix A. The preparation of the salt plugs and their emplacement in the test specimen are described in Appendix $B$. This process also provides the cavities with leakproof plastic liners. Calculations and experimental observations have shown that for time periods on the order of one month between machining and testing, the long-term creep of the plasticine can be ignored for all practical purposes and the salt plugs are unnecessary.

The risers also permitted the filling of the cavities with liquid. The top of the riser was at $90^{\circ}$ to the top, flat surface of the model. This design permitted the model to be turned on its side, for mounting onto the fixed platform of the centrifuge, without losing the liquid in the cavity. 
Test Fixtures

The fixtures used to support the plasticine model in the centrifuge were aluminum cylinders that had been designed for body force loads up to $150 \mathrm{~g}$ 's. The cylinders had removable tops and bottoms. The bottom was specially designed to support the specimen along a surface of constant gravity (body force) potential. As the centrifuge used in this study has a working radius of approximately $1.83 \mathrm{~m}(6 \mathrm{ft})$, the $\mathrm{fixture}$ bottom had a cylindrical inside surface. The other side of this bottom plate was flat to permit mounting of the entire fixture onto the centrifuge. The inside surface of the fixture had been sand blasted to insure a "no slip" condition along the bottom surface of the fixture. The lateral boundaries between the plasticine and the fixture were lined with Teflon to insure a very low coefficient of friction on these boundaries.

\section{Centrifuge}

The Sandia $\mathrm{CA}-2$ centrifuge, pictured in Figure 4, was used to conduct these simulations. This machine has a test radius that can range from $1.52 \mathrm{~m}$ (5 $\mathrm{ft}$ ) to $2.13 \mathrm{~m}(7 \mathrm{ft})$. A radius of $2.06 \mathrm{~m}$ was used for the experiments reported here. This machine has maximum rated capabilities of $227 \mathrm{~kg}$ (500 lb) static payload, $150 \mathrm{~g}$ acceleration, and $13,600 \mathrm{~g}-\mathrm{kg}(30,000 \mathrm{~g}-\mathrm{lb})$ dynamic load.

Fifty slip rings are available on this machine for data acquisition.

Single Cavity Experiments

The single cavity experiments were conducted in experimental fixtures that were $0.285 \mathrm{~m}(1125 \mathrm{in})$ inside diameter by $0.292 \mathrm{~m}(11.5 \mathrm{in}) \mathrm{high}$. All of the models were constructed using the green plasticine because it is the "best" material for simulating the salt (i.e., their stress exponents are the closest). Each was $0.254 \mathrm{~m}(10 \mathrm{in}) \mathrm{high}$ with a flat top. A single cavity was machined about the centerline of each of three specimens as shown in Figure 5 . The cavity was $50.8 \mathrm{~mm}$ ( $2 \mathrm{in}$ ) in diameter and $101.6 \mathrm{~mm}$ (4 in) high. Thus, the overburden and the underburden were $76.2 \mathrm{~mm}$ ( 3 in). The riser, in all cases, 


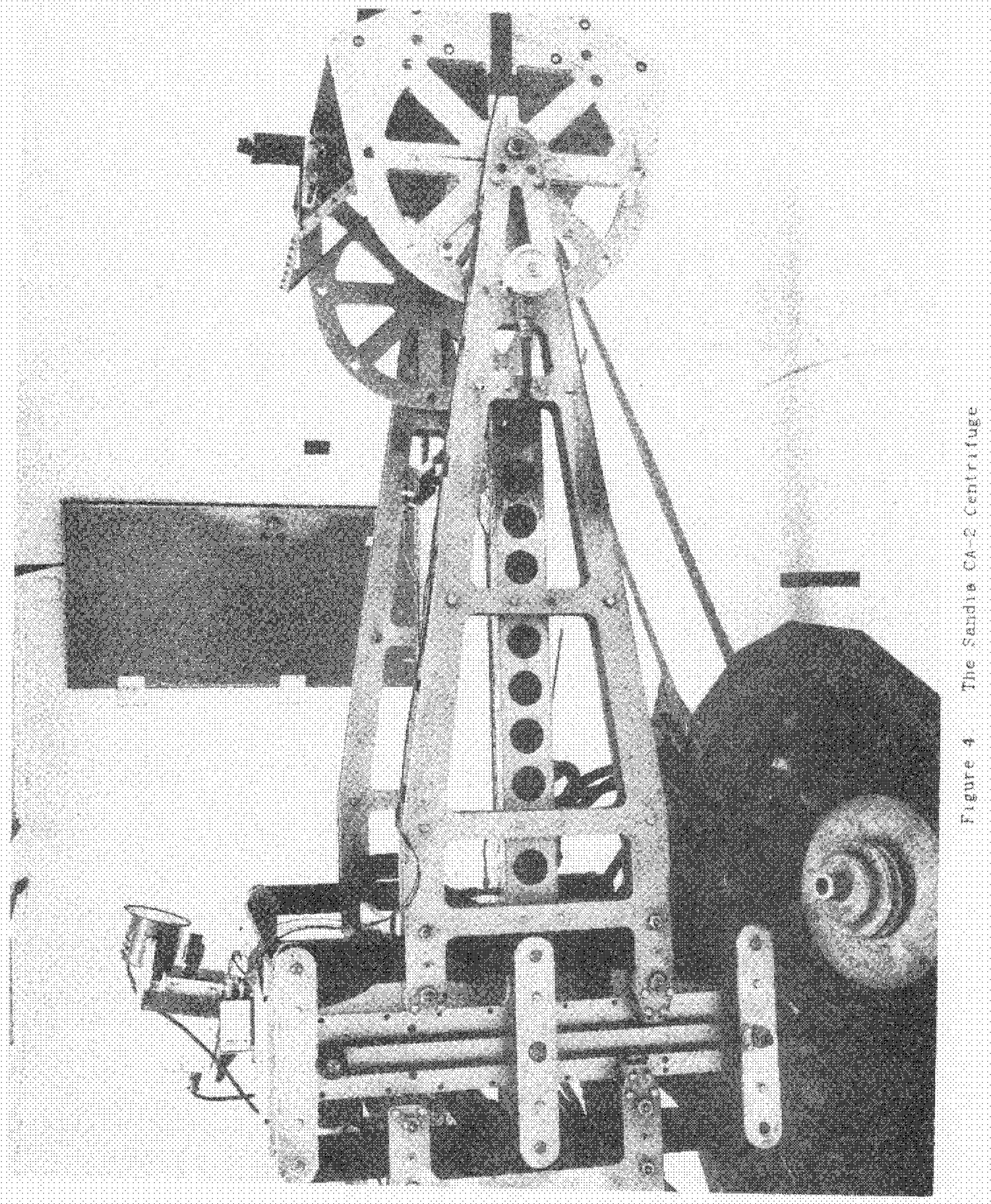




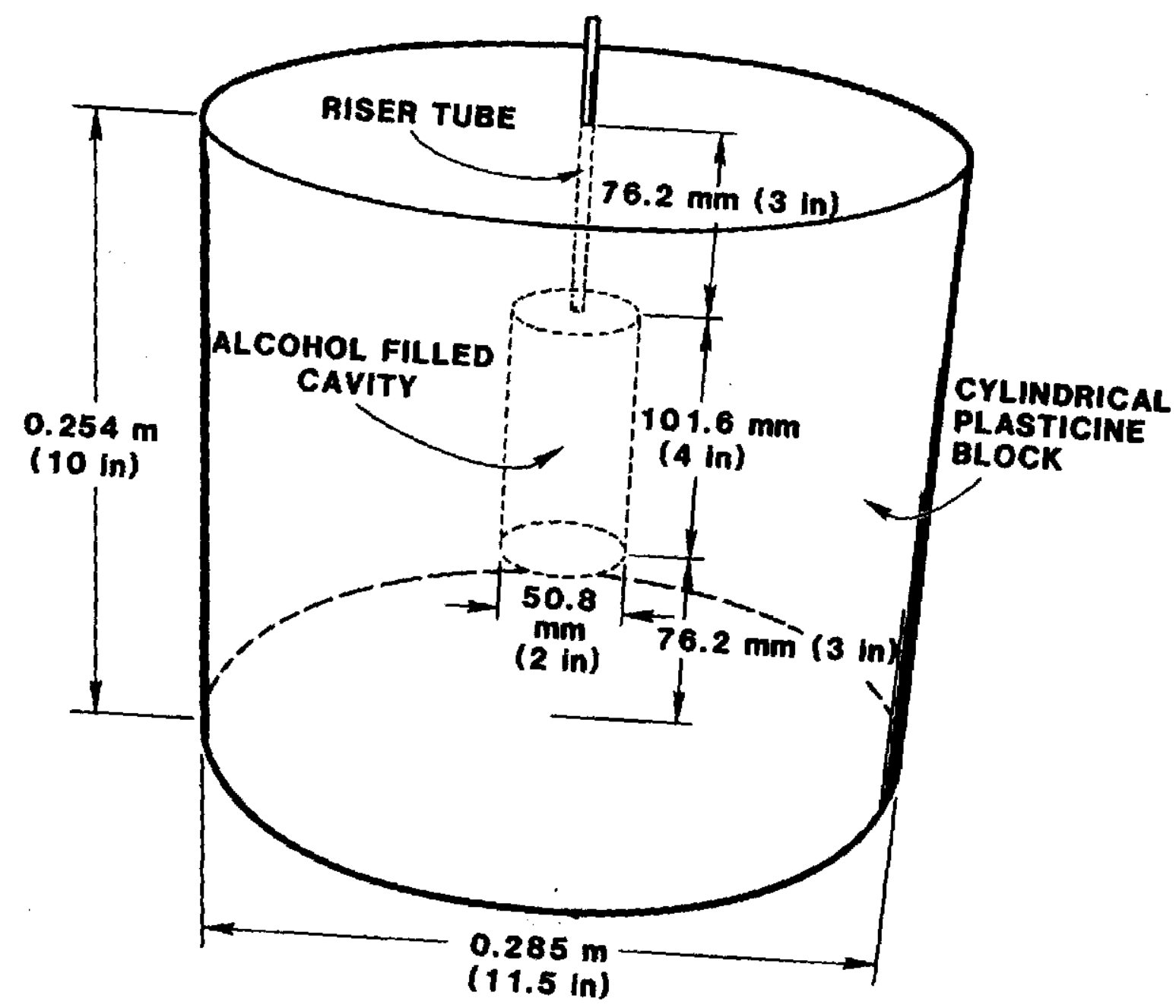

Figure

Schematic Diegram of the Single Cavity Experiments 
reached to a height of $117 \mathrm{~mm}(5.59 \mathrm{in})$ above the top of the cavity. To increase the overburden stress on the specimen, the upper surface of the specimen was covered with a single lead sheet that was $6.35 \mathrm{~mm}(0.25 \mathrm{in})$ thick. A layer of teflon was placed between the plasticine and the lead to yield a low coefficient of friction between them.

The tests were conducted for a nominal 2 hours each. Three models were tested, one each at loads of $100 \mathrm{~g}, 125 \mathrm{~g}$, and $150 \mathrm{~g}$. These experiments are designated as SE100, SE125 and SE150, respectively.

\section{Multi-Cavity Experiments}

The multi-cavity experiments were conducted in experimental fixtures that were $0.438 \mathrm{~m}(17.25 \mathrm{in})$ inside diameter by $0.292 \mathrm{~m}(11.5 \mathrm{in}) \mathrm{high}$. Two models were constructed using the green plasticine and one using the gray plasticine. The green plasticine offered the "best" simulation of the salt. The gray plasticine was used to check for systematic scaling errors. Each model was $0.254 \mathrm{~m}$ (10 in) high with a flat top. A single cavity was machined about the centerline of each specimen (Cavity A). The other three cavities (Cavities B. $C$ and $D$ ) in each specimen were machined symmetrically as shown in Figure 6 (i.e., at 120 degrees relative to one another). For the three models, the pillar to diameter ratio (p:d ratio) was varied from 0.5 to 1.0 to 1.5 . The ratio corresponds to pillar sizes of $25.4 \mathrm{~mm}(1 \mathrm{in}), 50.8 \mathrm{~mm}(2 \mathrm{in})$ and 76.2 mm ( 3 in), dimension $\mathrm{CC}$ in Figure 6 . The tests are designated as ME1, ME 2 and ME3, respectively. The first and last were constructed from green plasticine and the other from the gray plasticine. The plasticine overburden and underburden were $76.2 \mathrm{~mm}$ ( $3 \mathrm{in}$ ). The riser, in all cases, reached a height of $121 \mathrm{~mm}(4.75 \mathrm{in})$ above the top of the cavity. To increase the overburden stress on the specimen, the upper surface of the specimen was covered with eight lead sheets that had a combined thickness of $6.35 \mathrm{~mm}(0.25 \mathrm{in})$. A layer of teflon was placed between the lead and the plasticine. Thus, the singlecavity and the multi-cavity simulations were equivalent with the exception of the number and placement of the cavities.

The multi-cavity tests were conducted for a nominal 3 hours 15 minutes at $100 \mathrm{~g}$ 


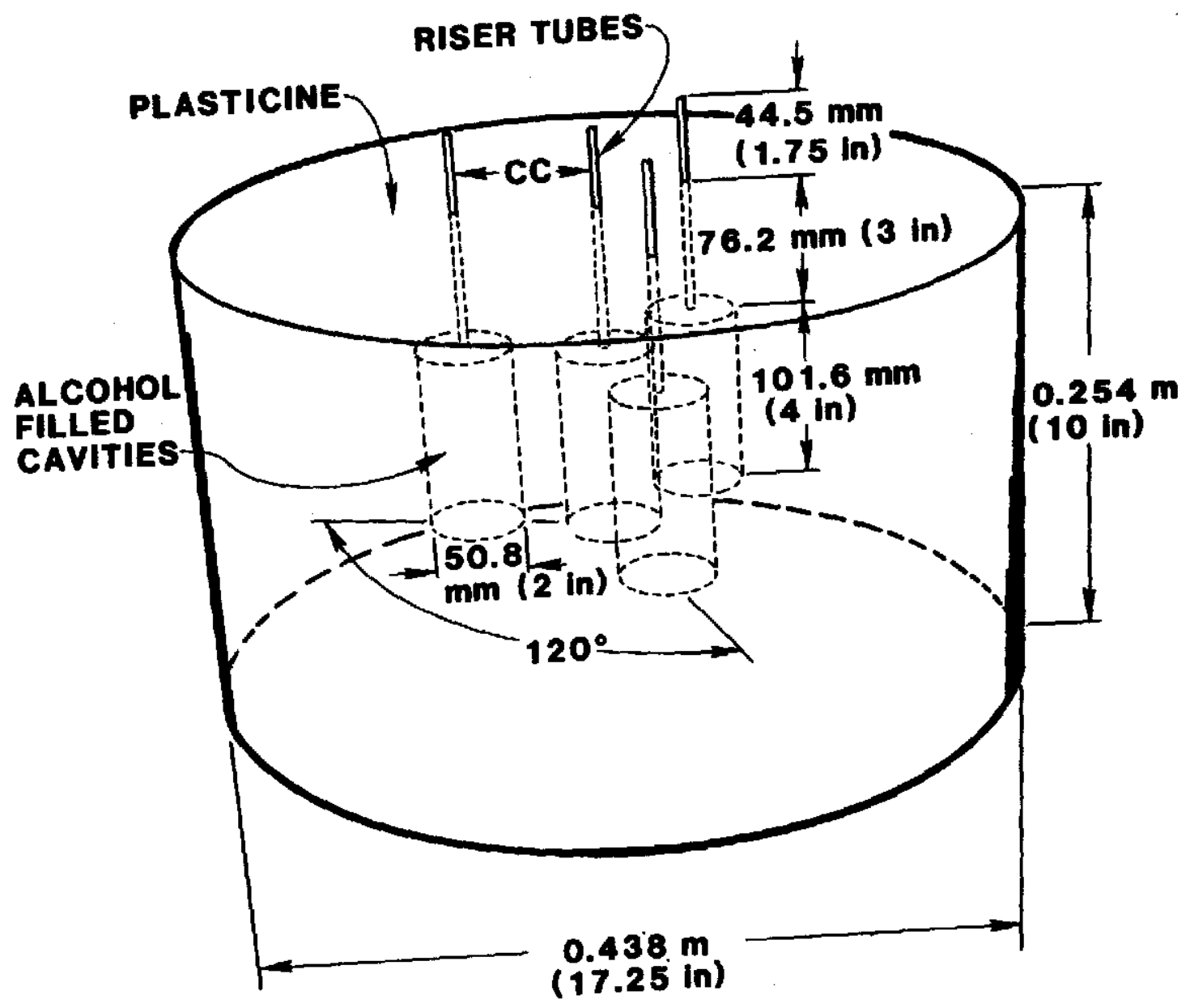

Figure 6: Schematic Diagram of the Multi-Cavity Experiments 
Post Test Analysis

After a simulation was completed, the model was stabilized by freezing. Then. the test fixture was removed and the model was sectioned in an appropriate manner. For the single cavity experiments, the model was sliced in half along a diameter to form two semi-cylindrical pieces. For the multi-cavity experiments, the model was sectioned first along a diameter through two cavities and then along two radil. Each cut was chosen to divide an "outlying" cavity in half. The first set of post-test cuts was designed to slice in half the center cavity and two of the surrounding cavities. Cutting all three of the surrounding cavities would cut the central cavity into thirds, making accurate volume calculation more difficult. After the volumes of the first three cavities were determined, the fourth cavity was cut, photographed and its volume calculated.

Representative photographs of these cross sections are shown in Figures 7 and 8

Digitizing

Each cavity was cut in half during the sectioning process and each half photographed. All photographs of each cavity, taken after test completion and sectioning, were digitized for computer calculation of final volume and for comparison of pillar deformation in the multi-cavity experiments. Digitizing was done on a Talos digitizing and light table using the computer program GRAFAID [4] which runs on a VAX $11 / 780$ computer. The coordinate system chosen placed the cavity approximately in the center of a $130 \mathrm{~mm}(5.125 \mathrm{in}$.) square area for the single cavity tests and a $127 \mathrm{~mm}(50 \mathrm{in.})$ square area for the multi-cavity tests. Each cavity was photographed with and without a 25.4 mm (1.0 in.) grid in front of the cavity. The photograph containing this grid was used to correct for vertical and horizontal stretch if it existed and to set the coordinate system. The digitized circumference of each cavity contained an average of 160 points. Figures 9,10 and 11 show the digitized cavity outlines from the single cavity experiments and Figures 12,13 and 14 show digitized outlines of the central cavity in each of the three multicavity experiments. 

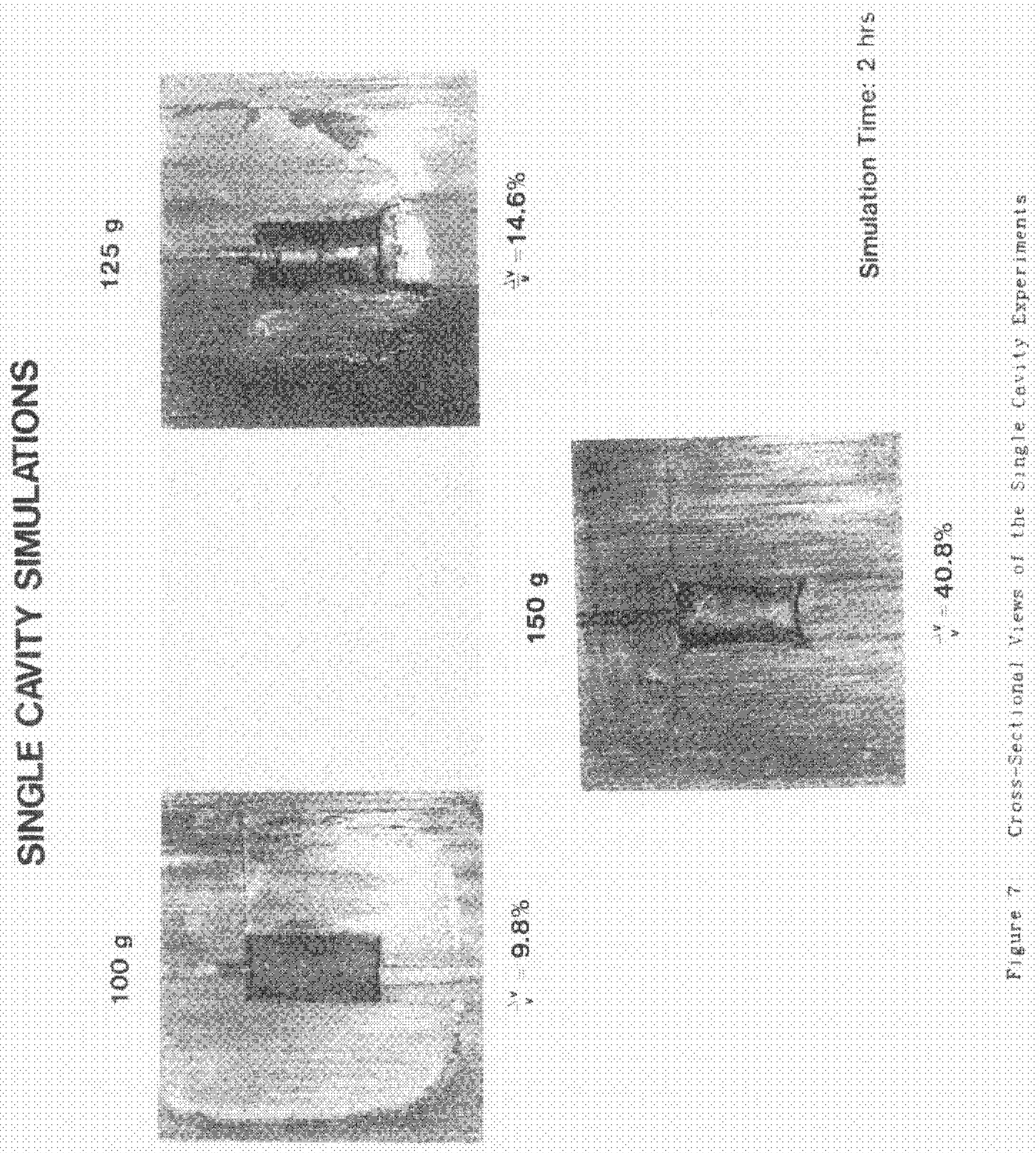


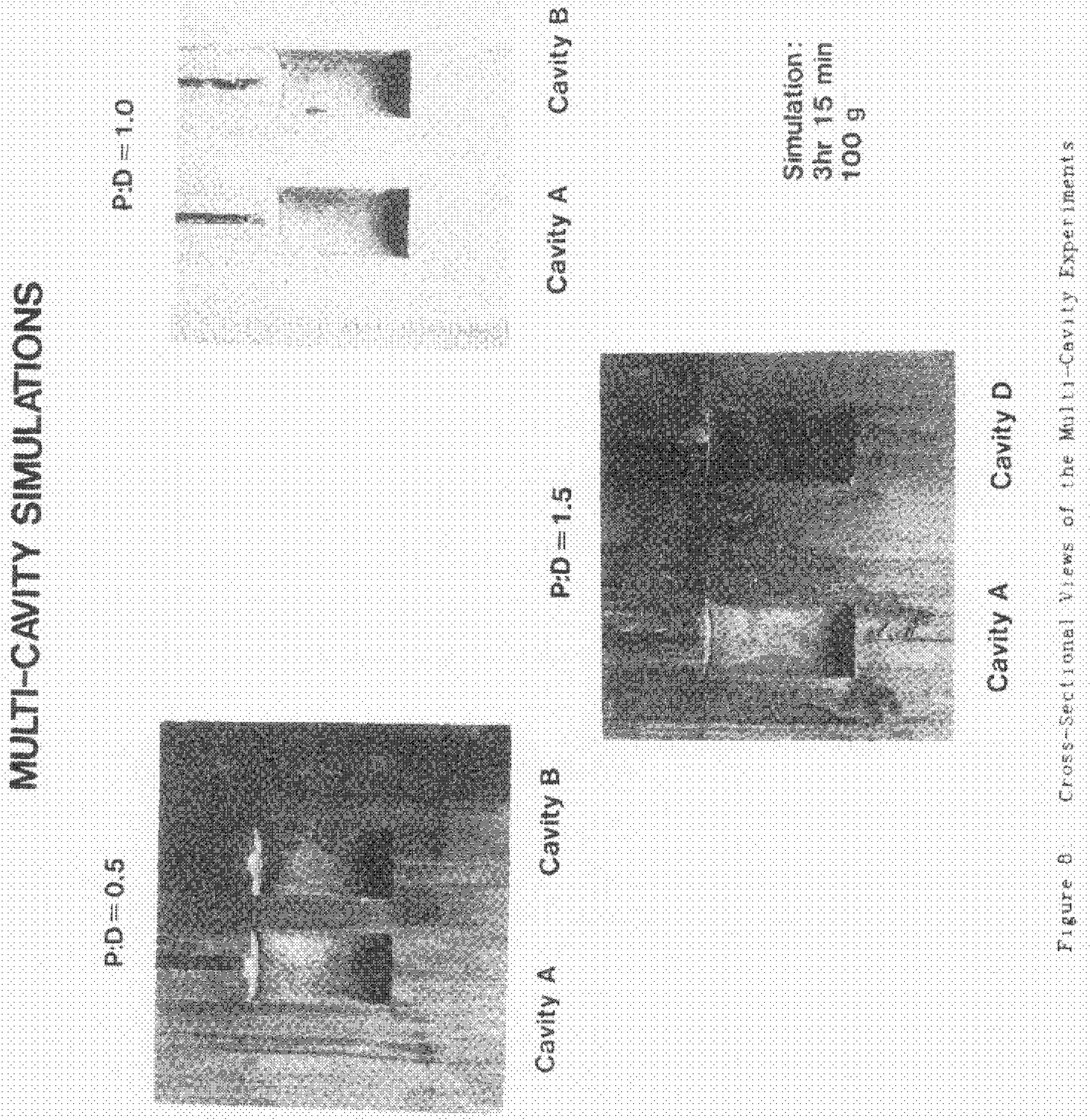




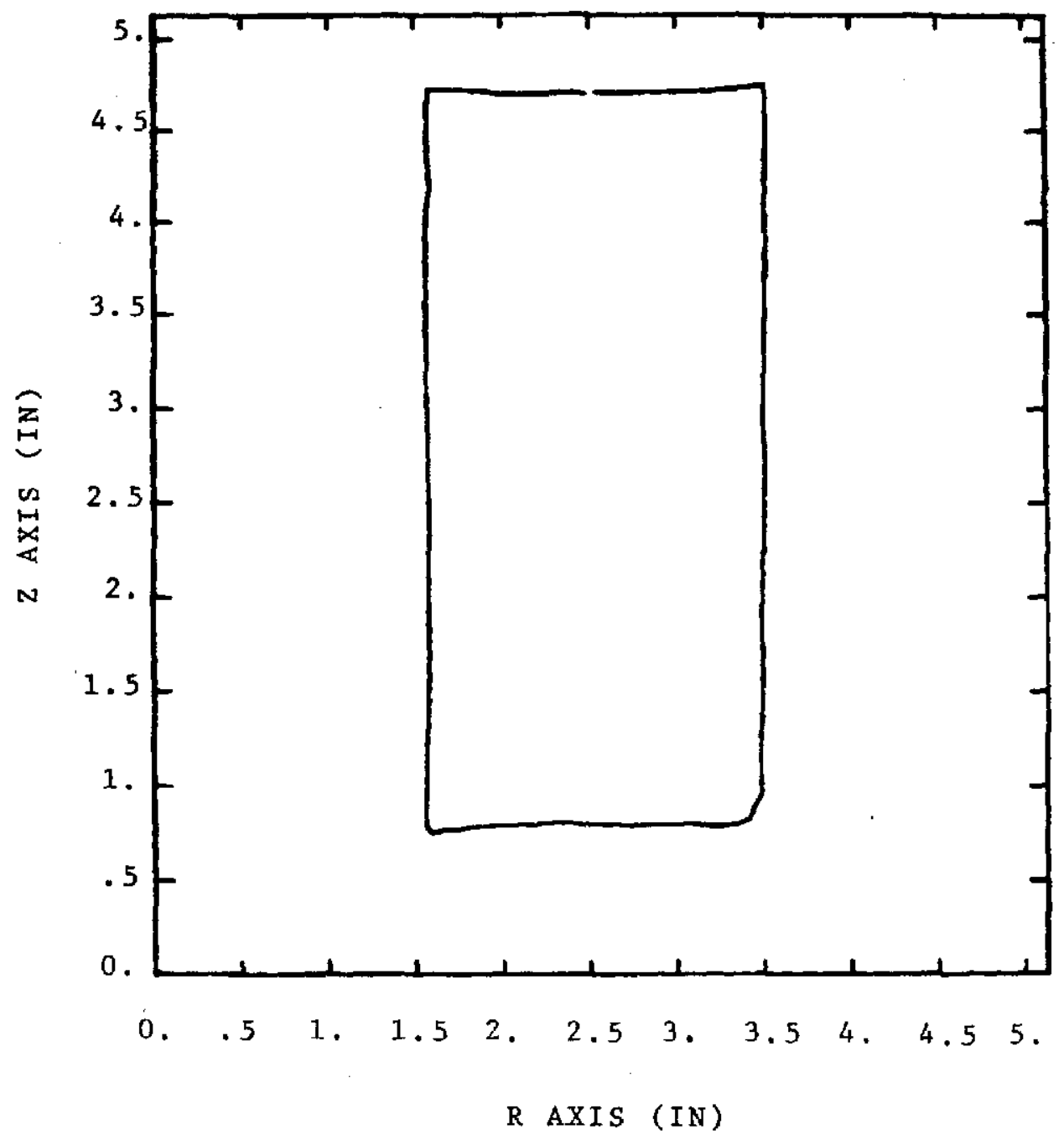

Figure 9: Digitized Cross Section from Cavity SE100 


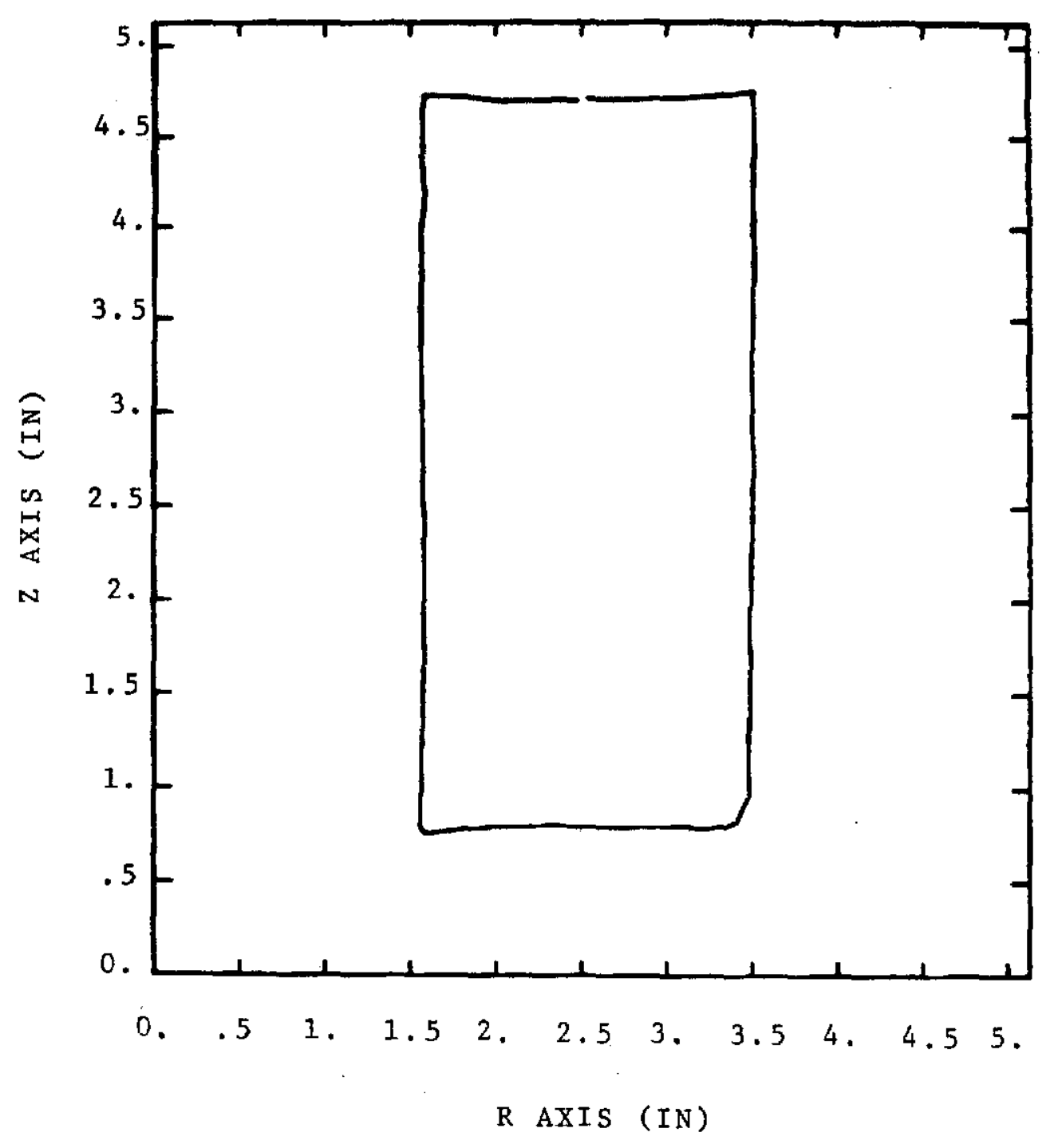

Figure 10. Digitized Cross Section from Cavity SE125 


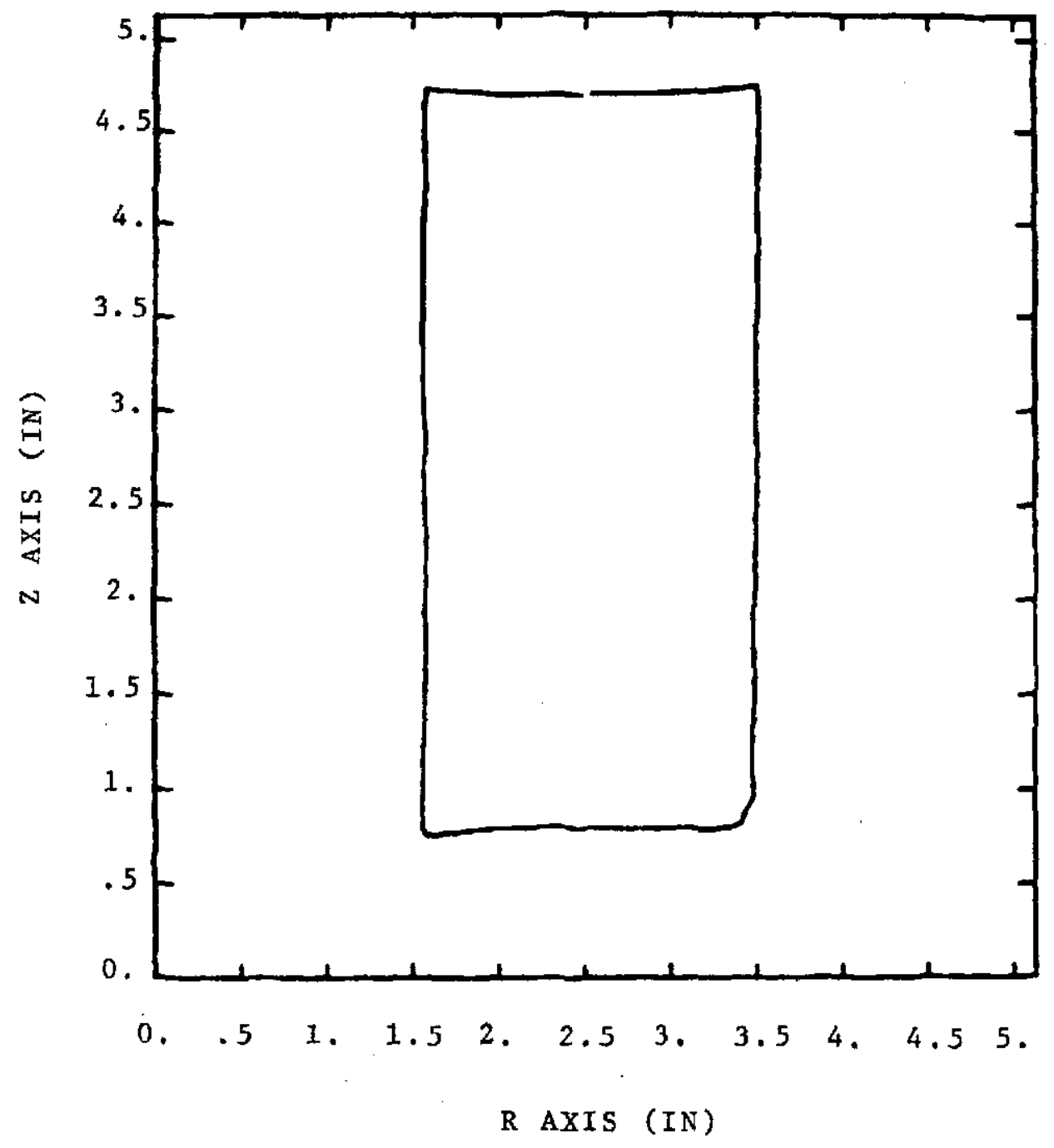

Figure 11. Digitized Cross Section from Cavity SE150 


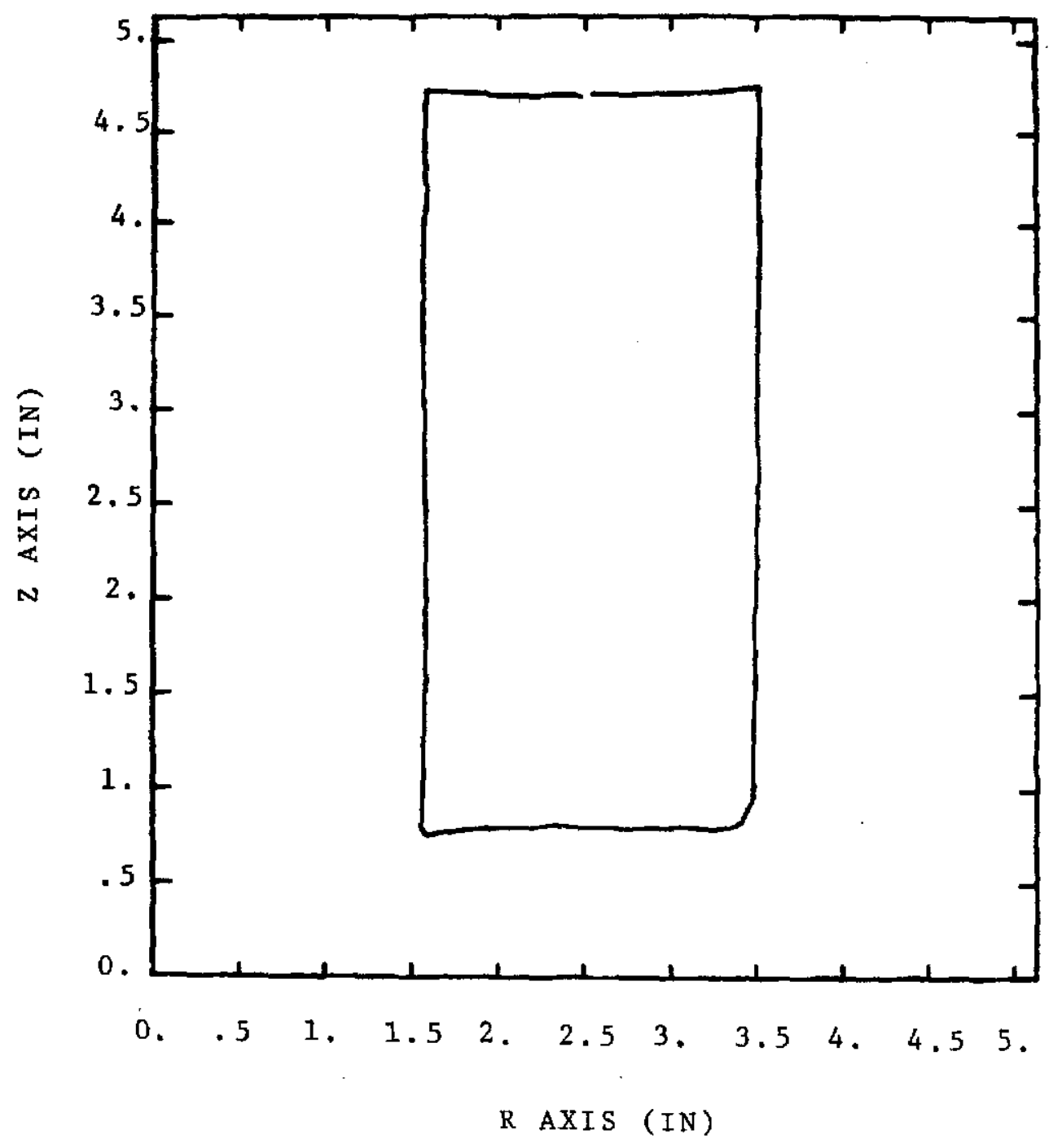

Figure 12: Digitized Cross Section from Cavity ME3A 


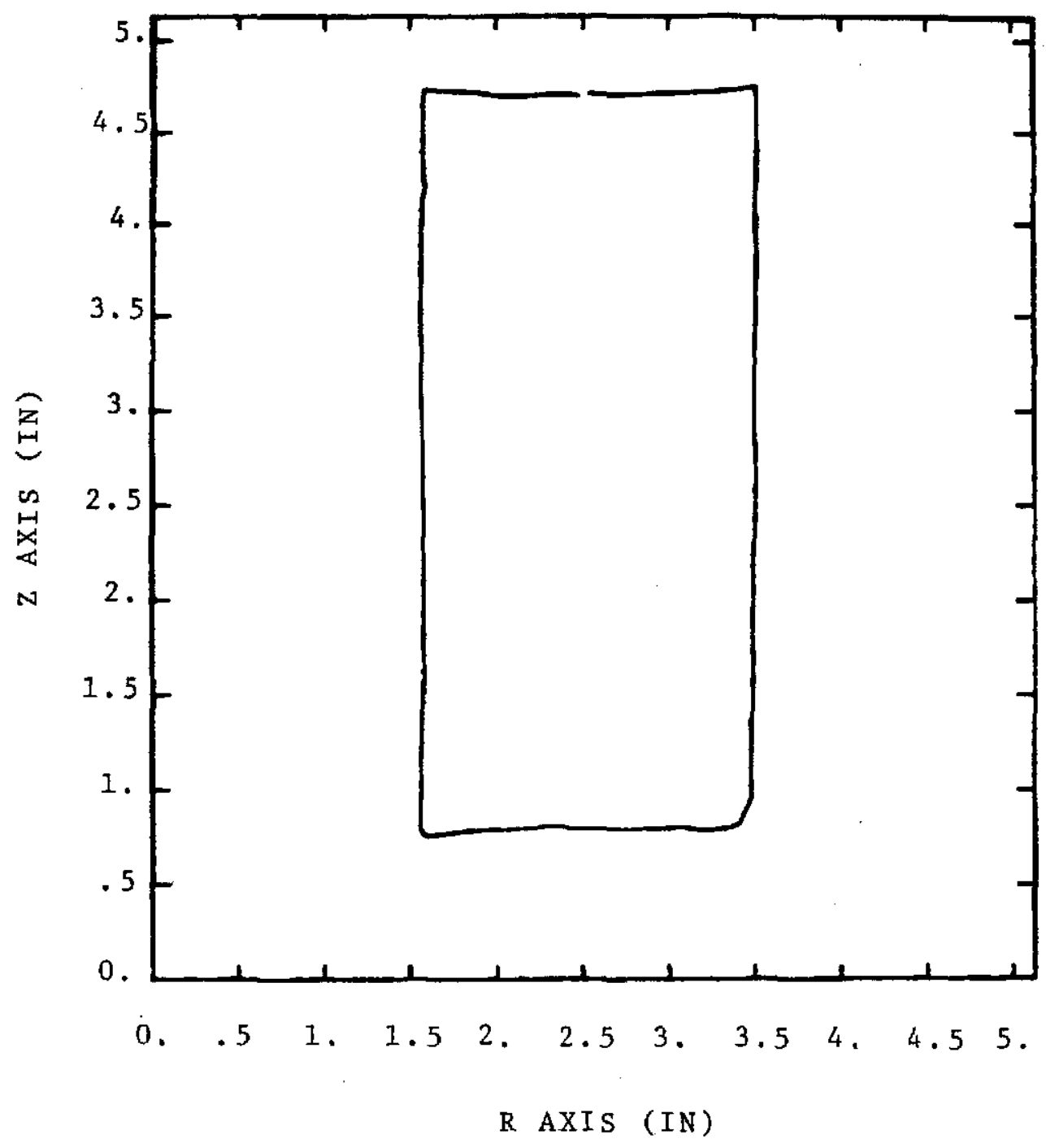

Figure 13: Digitized Cross Section from Cavity ME2A 


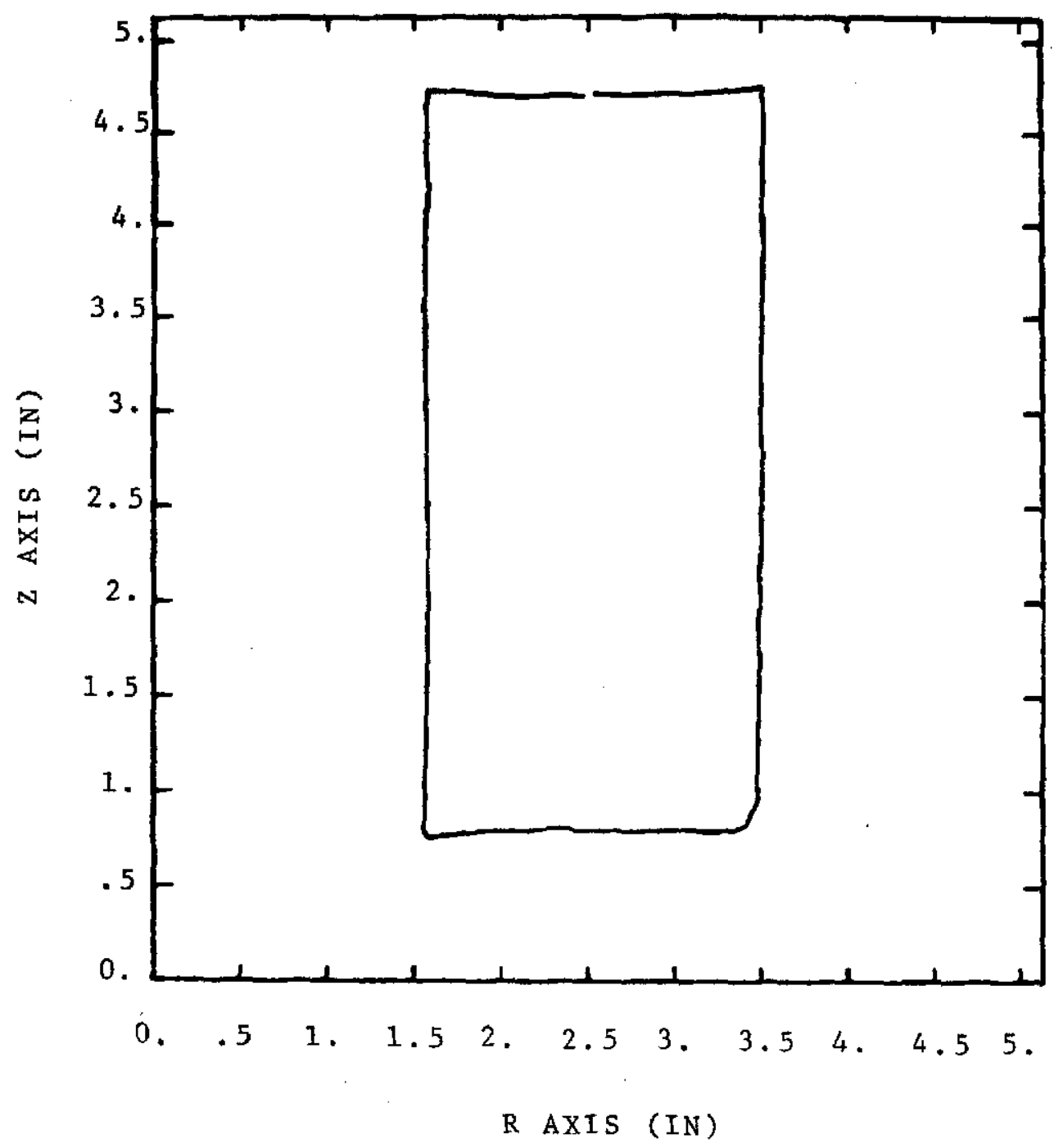

Figure 14. Digitized Cross Section from Cavity ME1A 
Volume Calculation

GRAFAID writes a disk file containing the digitized $r$ and $z$ coordinates for the two loops corresponding to each side of the cavity. A computer program called VOLCENT.FOR (Appendix $C$ ) was written to read this file and compute the cavity volume. First the coordinate loops are made axisymmetric by subtracting the $r$ coordinate of the first point (top center of cavity) from all the $x$ coordinates. Then the coordinates are again shifted (usually a small amount) based on the maximum and minimum $r$ coordinates on the loop. A compensation can then be made if the cut was not made through the center (maximum radius) of the cavity. This is done by expanding the $r$ coordinates according to

$$
r=\sqrt{\text { of } s t^{2}+r^{2}}
$$

where $r$ is the radial coordinate and of center.

Each loop is then split into a positive coordinate loop and a negative coordinate loop which results in four loops for each cavity. The volume is determined by assuming each loop is axisymmetric. The volume of an axisymmetric loop can be computed using the second theorem of Pappus-Guldinus [5].

$$
v=2 \text { pi } x \text { bar } A
$$

where xbar and $A$ are the radial centroid and area enclosed by the loop respectively. The centroid and area can be computed from the coordinates using

$$
A=-\sum_{i=0}^{n}\left(z_{i+1}-z_{1}\right)\left(R_{i+1}+R_{i}\right) / 2
$$

and 


$$
\overline{\mathrm{X}}=-\frac{1}{\mathrm{~A}} \sum_{\mathrm{i}=0}^{\mathrm{n}} \frac{1}{8}\left[\left(\mathrm{z}_{\mathrm{i}+1}-\mathrm{z}_{\mathrm{i}}\right)\right]\left[\left(\mathrm{R}_{\mathrm{i}+1}+\mathrm{R}_{\mathrm{i}}\right)^{2}+\frac{1}{3}\left(\mathrm{R}_{\mathrm{i}+1}-\mathrm{R}_{\mathrm{i}}\right)^{2}\right]
$$

where $Z$ is the vertical coordinate and $R$ is the radial coordinate of the ith point on the loop.

\section{Results}

The final cavity volumes calculated by the methods described above are found in Table Il for the single cavity tests and Table 111 for the multi-cavity tests. A volume is computed for each of the 4 loops mentioned previously. The mean and standard deviations of the four volumes are given for each cavity with the mean being the final cavity volume. The original volume is calculated from micrometer measurements taken before the centrifuge tests. The percent volume loss is calculated using the original and final cavity volumes. 


\section{Table 11}

Final Cavity Volumes for Single Cavity Tests. Test time 2 hours.

\begin{tabular}{|c|c|c|c|c|c|}
\hline Experiment & $\begin{array}{c}\text { Orig. Vol. } \\
\mathrm{cm}^{3} \\
\left(\mathrm{in}^{3}\right)\end{array}$ & $\begin{array}{c}\text { Final Vol. } \\
\mathrm{cm}^{3} \\
\left(\mathrm{in}^{3}\right)\end{array}$ & $\begin{array}{c}\text { Stand. Dev. } \\
\mathrm{cm}^{3} \\
\left(\mathrm{in}^{3}\right)\end{array}$ & $\% \operatorname{loss}$ & $\begin{array}{l}\text { Head Loss } \\
\text { mm } \\
\text { (in) }\end{array}$ \\
\hline SE 100 & $\begin{array}{c}210 \\
(12.8)\end{array}$ & $\begin{array}{c}189 \\
(11.5)\end{array}$ & $\begin{array}{c}54 \\
(0.3)\end{array}$ & 10. & NONE \\
\hline SE 125 & $\begin{array}{c}220 \\
(13.4)\end{array}$ & $\begin{array}{c}188 \\
(11.5)\end{array}$ & $\begin{array}{c}65 \\
(0.4)\end{array}$ & 15. & NONE \\
\hline $\mathrm{SE} 150$ & $\begin{array}{c}226 \\
(13.8)\end{array}$ & $\begin{array}{c}134 \\
(8.2)\end{array}$ & $\begin{array}{c}54 \\
(0.3)\end{array}$ & 41. & $\begin{array}{l}6.0[1] \\
(1.0)\end{array}$ \\
\hline
\end{tabular}

Note:

1. Dimensional analysis has been used to calculate the head loss. 
Table III

Final Cavity Volumes for Multi-Cavity Tests

Test time 3.25 hours, $15 \mathrm{~min}$ at $100 \mathrm{G}$ 's

\begin{tabular}{|c|c|c|c|c|c|c|}
\hline Experiment & Cavity & $\begin{array}{c}\text { Orig. } \text { \ol }^{3} \\
\left.\mathrm{~cm}^{3}\right)\end{array}$ & $\begin{array}{c}\text { Final }{ }^{3} \text { Vol } \\
\left.\mathrm{cm}_{3}^{3}\right)\end{array}$ & $\begin{array}{c}\text { St and }{ }_{3} \text { Dev } \\
\mathrm{cm}^{3} \\
(\text { in }\end{array}$ & $\%$ loss & $\begin{array}{c}\text { Head Loss } \\
\text { mm } \\
\text { (in ) }\end{array}$ \\
\hline ME 1 & A & $\begin{array}{c}207 \\
(12.6)\end{array}$ & $\begin{array}{c}183 . \\
(11.2)\end{array}$ & $\begin{array}{c}4 \\
(0.2)\end{array}$ & 11. & $\begin{array}{c}7.6[1] \\
(0.3)\end{array}$ \\
\hline ME 1 & B & $\begin{array}{c}205 \\
(12.5)\end{array}$ & $\begin{array}{c}182 \\
(11.1)\end{array}$ & $\begin{array}{c}3 . \\
(0.2)\end{array}$ & 11. & $\begin{array}{c}7.6[1] \\
(0.3)\end{array}$ \\
\hline ME 1 & $\mathrm{C}$ & $\begin{array}{c}207 \\
(12.6)\end{array}$ & $\begin{array}{c}188 \\
(11.4)\end{array}$ & $\begin{array}{c}3 . \\
(0.2)\end{array}$ & 9 & NONE \\
\hline ME 1 & $\mathrm{D}$ & $\begin{array}{c}207 \\
(12.6)\end{array}$ & $\begin{array}{c}187 \\
(11.4)\end{array}$ & $\begin{array}{c}8 \\
(0.5)\end{array}$ & 10. & NONE \\
\hline ME2 & A & $\begin{array}{c}204 \\
(12.4)\end{array}$ & $\begin{array}{c}193 . \\
(11.8)\end{array}$ & $\begin{array}{c}1 \\
(0.1)\end{array}$ & 5 . & NONE \\
\hline ME2 & B & $\begin{array}{c}203 \\
(12.4)\end{array}$ & $\begin{array}{c}189 \\
(11.5)\end{array}$ & $\begin{array}{c}4 \\
(0.3)\end{array}$ & 7. & NONE \\
\hline ME2 & $\mathrm{C}$ & $\begin{array}{c}205 \\
(12.5)\end{array}$ & $\begin{array}{c}192 \\
(11.7)\end{array}$ & $\begin{array}{c}4 \\
(0.2)\end{array}$ & 7. & [Z] \\
\hline ME2 & $\mathrm{D}$ & $\begin{array}{c}205 \\
(12.5)\end{array}$ & $\begin{array}{c}194 \\
(11.9)\end{array}$ & $\begin{array}{c}1 \\
(0.1)\end{array}$ & 5. & [2] \\
\hline ME3 & A & $\begin{array}{c}208 \\
(12.7)\end{array}$ & $\begin{array}{c}166 \\
(10.1)\end{array}$ & $\begin{array}{c}4 \\
(0.3)\end{array}$ & 20 . & $\begin{array}{c}69 .[1] \\
(2.7)\end{array}$ \\
\hline ME3 & $\mathrm{B}$ & $\begin{array}{c}210 \\
(12.8)\end{array}$ & $\begin{array}{c}135 \\
(8.2)\end{array}$ & $\begin{array}{c}10 \\
(0.6)\end{array}$ & 36. & $\begin{array}{c}119 .[1] \\
(4.7)\end{array}$ \\
\hline ME3 & $\mathrm{C}$ & $\begin{array}{c}211 \\
(12.9)\end{array}$ & $\begin{array}{c}181 \\
(11.1)\end{array}$ & $\begin{array}{c}6 \\
(0.4)\end{array}$ & 14 & $\begin{array}{c}25 .[1] \\
1.0\end{array}$ \\
\hline ME3 & $\mathrm{D}$ & $\begin{array}{c}211 \\
(12.9)\end{array}$ & $\begin{array}{c}181 \\
(11.1)\end{array}$ & $\begin{array}{c}7 \\
(0.4)\end{array}$ & 14 & $\begin{array}{c}25 .[1] \\
1.0\end{array}$ \\
\hline
\end{tabular}

Notes:

1. The average head loss has been calculated for the green plasticine experiments using dimensional analysis.

2. There is not sufficient data to determine the head loss for the gray plasticine experiments using dimensional analysis. 
DIMENSIONAL ANALYSIS

As discussed by Ramberg [1], dimensional analysis is an important tool for relating the response of a small scale centrifuge model to that of a full scale (prototype) structure. The primary concern here is to determine the scaling relation between model time and prototype time. Using Dixon's [7] techniques, the scaling relation for time can be determined directly from the constitutive equations for the plasticine (Figure 3 ) and salt.

The constitutive equation for salt from various SPR sites has been determined by Wawersik and Zeuch [8]. The constitutive equation they use to describe the salt has the form

$$
\dot{\mathrm{e}}=A_{0} \exp (-Q / R T)\left(S_{T}\right)^{n} \quad
$$

where the $A_{0}$ is the leading coefficient, $Q$ is the activation energy, $R$ is the gas constant, $T$ is the temperature, and $n$ is the stress exponent. For this report, we will concentrate on the salt from the West Hackberry site. Its constitutive constants are $A_{0}=2.92 \mathrm{E}-231 /\left[\right.$ day $\left.(\mathrm{psf})^{\mathrm{n}}\right], Q=12.0 \mathrm{Kcal} / \mathrm{mole}{ }^{\circ} \mathrm{K}$, and $n=4.90$. Based on temperature logs from the West Hackberry site, the temperature of the salt is estimated to be $46.1^{\circ} \mathrm{C}\left(115^{\circ} \mathrm{F}\right)$. The resulting constitutive relation is shown graphically in Figure 15.

Scaling Relation on Time

One technique for relating the model time to the prototype's homologous time is dimensional analysis. Following the discussions in References [1], [7], [9] and [10], the ratio of the model time $t_{m}$ to the prototype time $t_{p}$ is called the time ratio $t_{r}$. As the strain scales $1: 1$ between prototype and model, the time ratio can then be written as

$$
t=\left(t_{m} / t_{p}\right)=\left(\dot{e}_{p} / \dot{e}_{m}\right)
$$

where the subscripts $p$ and $m$ imply prototype and model respectively. To determine homologous strain rates between the salt and the plasticine requires 
LOG [PROTOTYPE LONGITUDINAL STRAIN RATE, $\mathbf{s}^{-1}$ ]

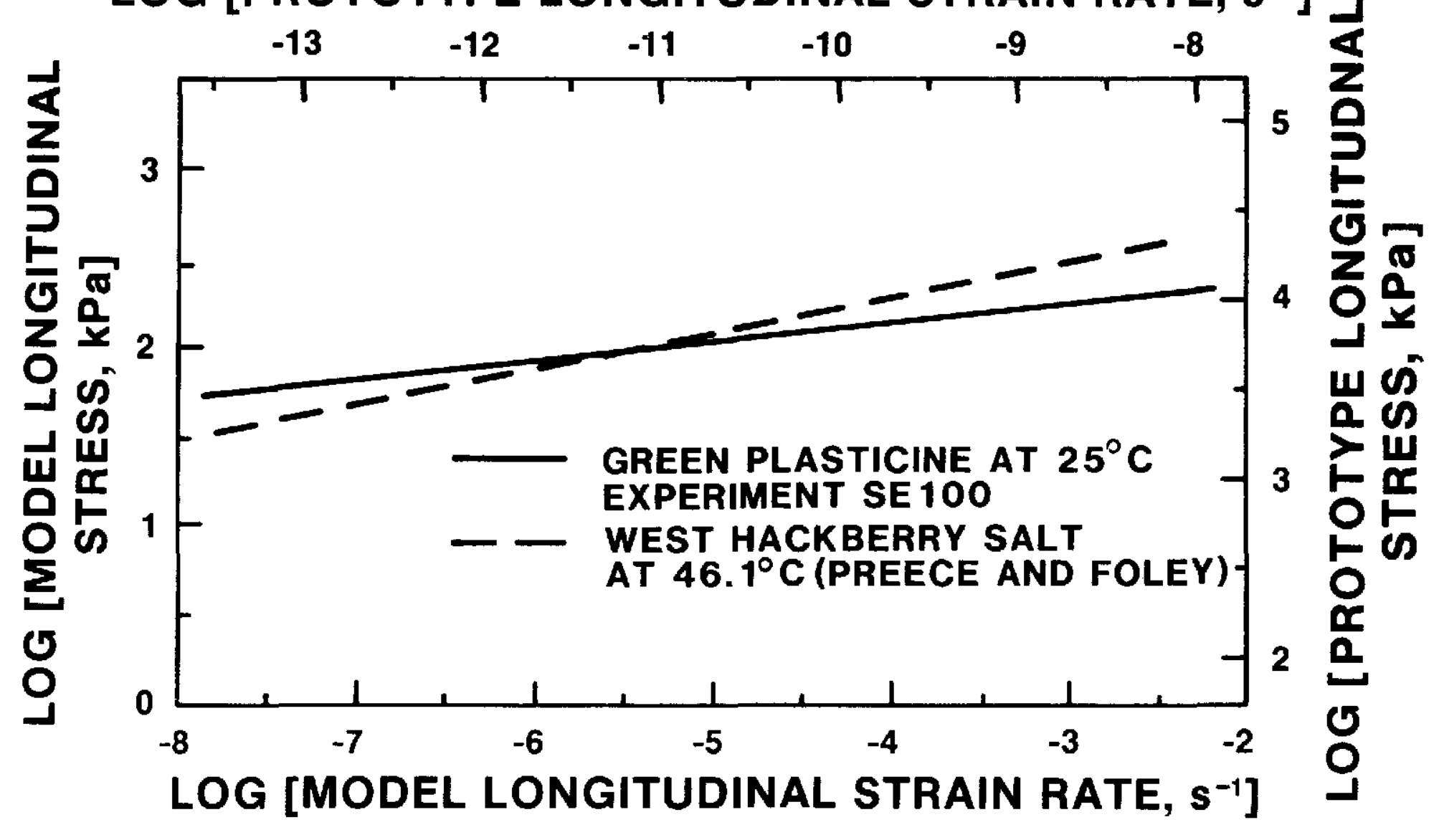


relating the volume change in the model to that in the prototype. By assuming that the average closure rate (equivalent to the average strain rate) in the creeping cavity is uniform for the cavity and neglecting second order terms, the relationship between the volume closure rate $\dot{v}$ and the linear closure rate $\dot{e}$ is given by

$$
\dot{\mathrm{V}}=3 \dot{\mathrm{e}}
$$

Prototype Cavity

The cavity chosen for the prototype is the West Hackberry 11 (WH11) Cavern. This cavern was chosen because it is a well-proportioned cavity as shown in Figure 16, and it is more than $305 \mathrm{~m}$ (1000 ft) from any other cavern [11]. This separation distance eliminates effects from cavern interaction and WH1 1 can be treated as a single cavern in an infinite medium. Volumetric closure of this cavity has been determined by a significant amount of wellhead pressure data. The average pressure $\mathrm{rise}$ is approximately $7.6 \mathrm{kPa} / \mathrm{day}$ ( $1.1 \mathrm{psi} / \mathrm{day})$. Of this, $5.5 \mathrm{kPa} /$ day $(0.8 \mathrm{psi} /$ day) has been attributed to thermal expansion of fluid in the cavern [13]. This leaves approximately $2.1 \mathrm{kPa} /$ day $(0.30 \mathrm{psi} /$ day) pressure rise due creep closure.

The volumetric closure rate has been calculated by Preece and Foley [12] using the finite element method. The finite element creep analysis simulated the cavern from the time of its leaching in 1962 through 1980 and predicted a pressure rise of $2.3 \mathrm{kPa} /$ day $(0.34 \mathrm{psi} / \mathrm{day})$ in 1980 . This computed volumetric closure rate was $2.31 \mathrm{~m}^{3} /$ day $\left(81.7 \mathrm{ft}^{3} / \mathrm{day}\right)$. The volume loss rate in percent based on a cavern volume of $1.24 \mathrm{E} 6 \mathrm{~m}^{3}\left(4.38 \mathrm{E} 7 \mathrm{ft}^{3}\right)$ is taken to be a nominal 0.5 percent in 6 years. 


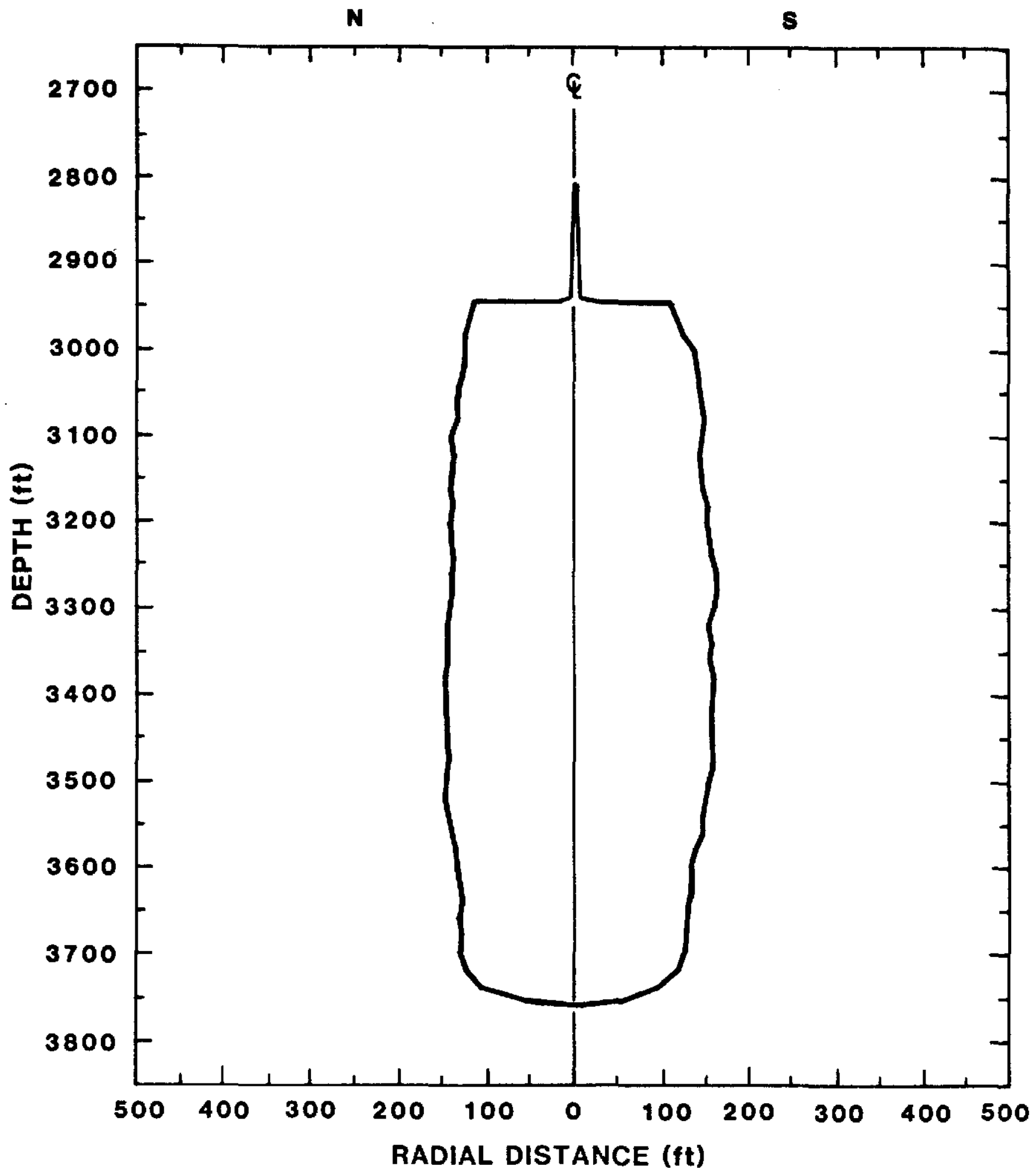

Figure 16: Cross section of West Hackberry Cavern 11

39 
For the average volume reduction for the West Hackberry 11 Cavity (WH11) of $0: 5$ percent in 6 years, the equivalent average linear closure rate (as defined by Equation 11) is $8.82 \mathrm{E}-12 / \mathrm{s}$. We want to compare this value with the model simulation. For Cavity SE100, the average volume reduction was 9.79 percent (see Table II) in 2 hours. Its average linear strain rate is then $4.53 \mathrm{E}-6 / \mathrm{s}$. Using Equation 10 yields a time ratio of $1.94 E-6$ (this equivalence is shown graphically in Figure 15). Thus, the model time of 2 hours converts to a homologous prototype time of 117 years. A similar analysis of Cavity SE125 yields a homologous time of 175 years. Although Cavity SE150 suffered a loss of fluid head during the course of the experiment (discussed later), the data from this experiment can still be used in this dimensional analysis because the equivalence between the experiment and prototype is only a function of the average strain rate observed in the cavity. For SE150, the average linear strain rate is $1.89 \mathrm{E}-5$; which corresponds to a homologous prototype time of 489 years. Thus, the effect of a head loss is to increase the time shift from that for a full head. These time data are plotted in Figure 17.

By assuming that the cavity interactions in the multi-cavity experiments are limited to changes in the average strain rate observed in a particular cavity, the multi-cavity experiments can also be analyzed as described above. For cavities ME1C and ME1D (both with assumed full fluid heads during the course of the experiment) the homologous times are 113 years and 116 years, respectively. The equivalence between these tests and the wH1 1 Cavity are shown graphically in Figure 17.

The homologous prototype time results for all of the experimental cavities are summarized in Figure 18.

Average Driving Stress Analysis

The dimensional analysis for the cavities with full fluid heads may also be used to determine the effects of a reduced head on the volume loss. As discussed by Preece and Sutherland [6] and in Appendix D, the effective stress 




Figure 17. Effect of a Reduced Fluid Head on the Measured Volume Loss 


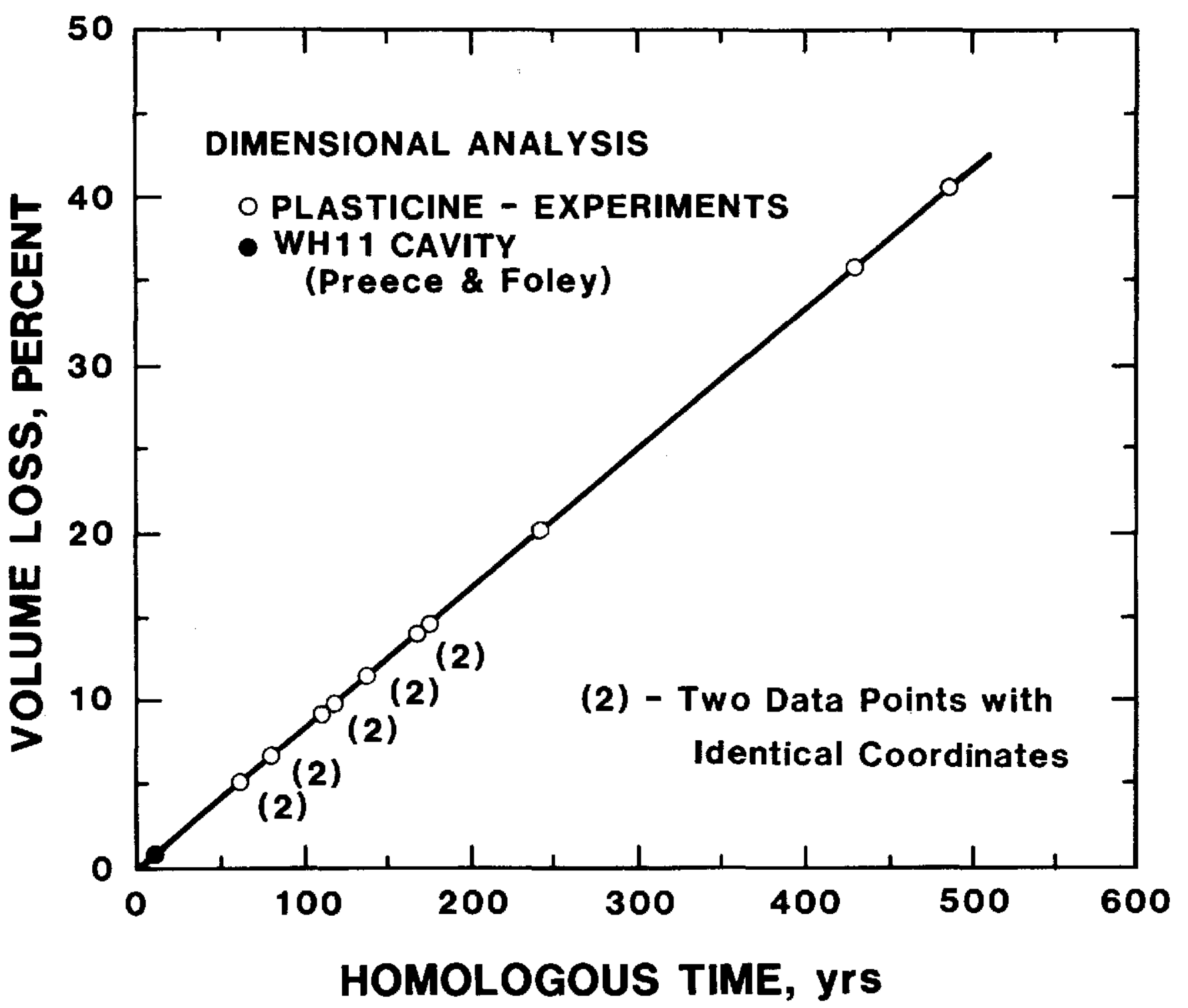

Figure 18: Volume Loss Predictions Based on an Extrapolation of the West Hackberry Cavern 11 Data 
that causes the plasticine to creep changes during the course of an experiment. This driving stress $S_{D}$ starts with a value $S_{0}$, equal to the overburden pressure less the fluid head.

The functional relationship between $S_{D}$ and $S_{0}$ may be determined accurately for a given material (e.g., green plasticine) using numerical techniques. However, another similar approach uses the data from simulations with a known fluid head to determine the "average" driving stress for the entire experiment with changing fluid head. For the full head experiments, the value of $S_{0}$ can be easily calculated from the experimental parameters. The average driving stress for that particular experiment can also be determined via the constitutive relation for the plasticine and the known average strain rate for the experiment. For the single cavity experiments using green plasticine, the relation between the two stresses is shown in Figure 19. By assuming that the slope of this linear relation does not change with time, a similar relation can be drawn for the the multi-cavity experiments in green plasticine, also see Figure 19. There is not sufficient data to construct a similar plot for the gray plasticine.

During the SE150 simulation, the riser broke during the course of the experiment. The average driving stress analysis permits us to determine both the volume reduction if the riser had not broken and the average height to which the fluid level fell during the experiment. For the first case, the initial driving stress $S_{0}$ for the full head would be $232 \mathrm{kPa}$ (33.6 psi). Figure 18 yields an average driving stress of $105.8 \mathrm{kPa}(15.35 \mathrm{psi})$. From Figure 3 , this stress level produces an average linear strain rate of $1.12 \mathrm{E}-5 / \mathrm{s}$. For the test time of 2 hours, the volume loss is 24.2 percent. This result is plotted in Figure 17. As discussed by Preece and Sutherland [6] and in Appendix D, the numerically determined value is 21.2 percent.

This simple procedure can be reversed for the measured volume loss of 40.76 percent (SE150) to yield a homologous prototype time of 489 years, see Figure 17. This prototype time implies that an average of $19 \mathrm{~mm}(0.75 \mathrm{in}$ ) of fluid head was lost during the course of the experiment, see Figure 5 . 


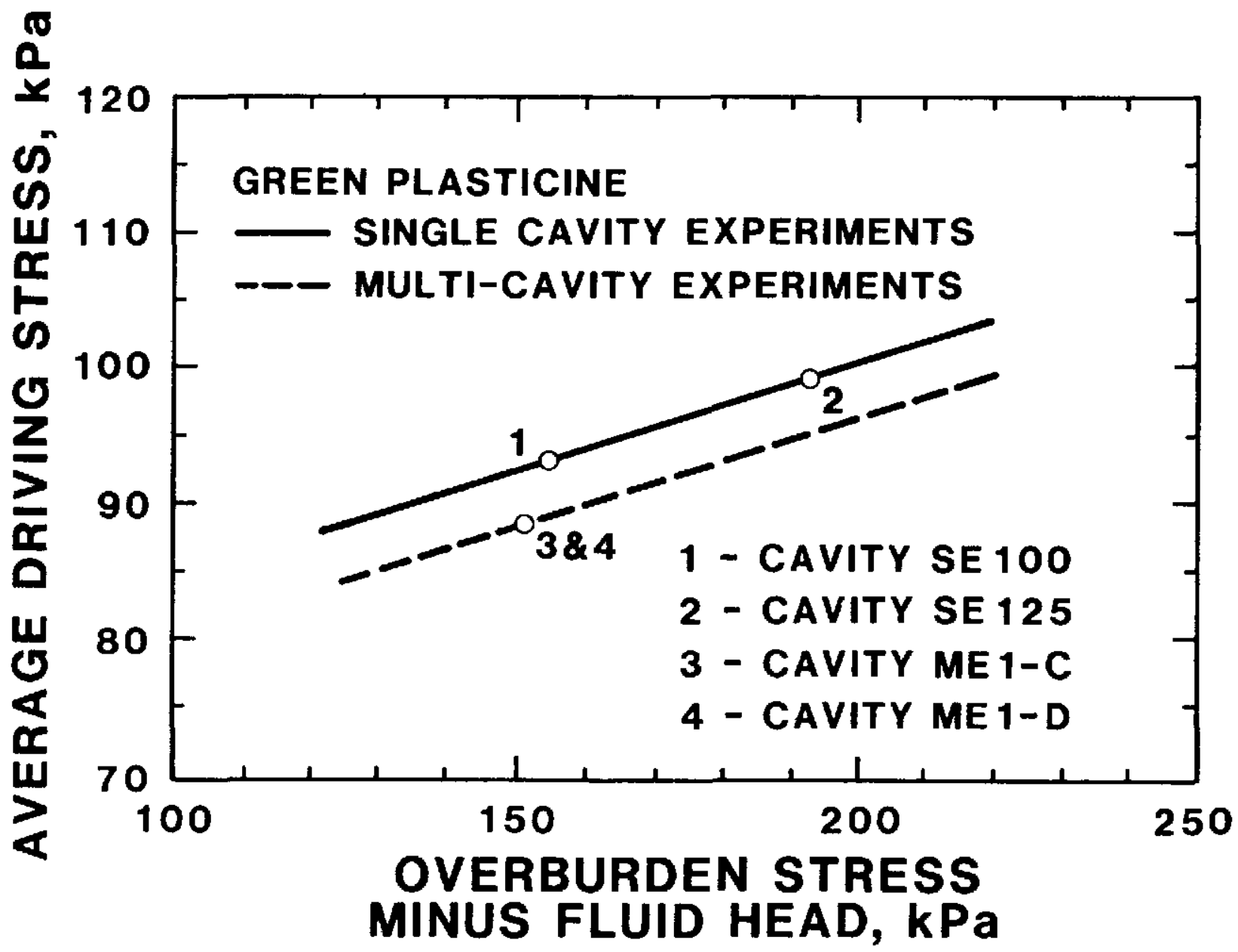

Figure 19: Average Driving Stress for Green Plasticine 
Similar analyses for Cavity ME1A and ME1B show an average head loss of $7.6 \mathrm{~mm}$ $(0.3 \mathrm{in})$ and a homologous prototype time of 137 years.

The head loss for each of the green plasticine experiments is summarized in Table II and III (Note: This calculation cannot be performed for the gray plasticine because there is not sufficient data to determine the relationship between the average driving stress and the total stress for this material.)

\section{Remarks}

The dimensional analysis results cited in this section yield consistent scaling relations for all of the cases analyzed. This approach, called "modeling of models" [9], verifies the self-consistency of the centrifuge simulations; however, we should emphasize that while the simulations are selfconsistent, their extension to a prototype cavity is only as good as the data for the prototype. The WH1l data used here is for the last $f$ ew years of the cavity's eighteen-year life and should, we believe, represent the cavity at steady state. We have used several simulations at different $g$ levels and different times to predict the response of the WH11 prototype cavern.

Discussion of Results

As shown in Figures 17 and 18 , the single cavity simulations provide a consistent set of simulations. In particular, the dimensional analysis illustrates that they are self-consistent and the finite element analysis, Appendix $D$, lllustrates that the results may be predicted using the constitutive description developed here for the plasticine. The results are somewhat confused by the head loss in simulation SE150; however, both analysis techniques are able to evaluate the influence of this experimental difficulty.

As shown in Figures 17-19, the multi-cavity experiments also present a consistent set of simulations. The dimensional analysis forms a consistent evaluation of the volume closure rates for both changes in fluid heads and different materials. Based on the dimensional analysis, cavities ME1C and 
MEID simulate the volume reduction in green plasticine for no head loss; i.e., approximately 9.5 percent, see Table III, for the simulation conditions used in the multi-cavity experiments. For gray plasticine, the volume reduction is approximately 5 percent for no head loss, 1 .e., cavities ME2A and ME2D.

As shown in Figures 8 and 14, the pillars in the ME1 experiment have deformed differently from the pillars in the other two multi-cavity experiments; namely, the pillars have a bulge in thejr bottom half. A close examination of the three pillars in this simulation illustrates that the bottom corner of the cavity has essentially not moved. This yields a pillar that is $25.4 \mathrm{~mm}$ (1 inch) wide; i.e., unchanged from the initial condition. Approximately 25 percent up the pillar, its width has increased by approximately 10 percent. Above there, its width decreases. At the top corner of the cavity, the pillar is approximately 5 percent oversize. For the ME2 and ME3 simulations, the bottom corner of the cavity did remain fixed, but the expansion of the pillar was more or less uniform over the remainder of the pillar.

In conclusion, we must emphasize that the extension of this simulation data set to SPR cavities is based on a single data point from the West Hackberry site. The physical simulations are self-consistent and can be presented as a function of prototype time, as was done in Figure 18. However, this figure should be viewed as a check of the self-consistency of the simulations and the available prototype data. It should not be used to infer long-term volume closure rates because the single prototype data point has had to be extrapolated over a hundred fold to encompass these simulations.

Further, we must emphasize that the simulations were conducted using a single aspect ratio for the cavities. The change in the deformation mechanism observed in the ME1 simulation is a function of the cavity's aspect ratio as well as the $P: D$ ratio. Thus, these data illustrate that the change in mechanisms we observed between a P:D ratio of 0.5 and 1.0 are valid only for the particular aspect ratio of 2.0 used here; i.e., a $50.8 \mathrm{~mm}$ diameter by $101.6 \mathrm{~mm}$ height. 


\section{CONCLUDING REMARKS}

In this manuscript, we have presented the results of 6 centrifuge simulation experiments that investigate the creep closure of fluid-filled cavities. Three of the experiments were conducted with a single, centerline cavity, and three were conducted with a symetric array of three cavities surrounding a central cavity. The self-consistency of the experiments was checked using dimensional analysis. Dimensional analysis is also used to relate the experimental results to a "homologous" time for a prototype cavity (WH11). As described in detail in the manuscript, the extension of the experiments to the prototype is based on the single data point from the West Hackberry site and requires several assumptions. Thus, the direct extension of the experimental data presented here should not be viewed as a prediction of the long-term behavior of fluid-filled cavities in salt. 


\section{ACKNOWLEDGMENTS}

The authors are indebted to Paul Hetch, who conducted the constant strain rate experiments on plasticine, and to Carl Goodrich, Tim George, Jim Ross and Eugene Chavez for their assistance in performing the experiments. 
1. H. Ramberg, Gravity, Deformation and the Earth's Crust, Academic Press, London, 1981 .

2. K. R. McClay, "The Rheology of Plasticine", Tectonophysics, Vol. 33, 1976, pp. T7-T15.

3. S. H. Crandall, L. G. Kurzweil, and A. K. Nigarn, "On the Measurement of Poisson's Ratio for Modeling Clay", Experimental Mechanics, Sept 1971, pp. $402-407$.

4. C. R. Adams, GRAFAID User's Manuel, to be published as a SAND report, Sandia National Laboratories.

5. F. P. Beer and E. R. Johnson, Vector Mechanics for Engineers: Statics, McGraw Hill Book Company, 1972 .

6. D. S. Preece and H. J. Sutherland, "Physical Simulations of FluidFilled Cavities in a Creeping Material", Proceedings of the 26th Rock Mechanics Symposium. South Dakota School of Mines, Rapid City, South Dakota, June 1985, pp. 507-514.

7. J. M. Dixon and J. M. Summers, "Recent Developments in Centrifuge Modeling of Tectonic Processes: Equipment, Model Construction Techniques and Rheology of Model Materials", J. of Structural Geology, submitted for publication.

8. W. R. Wawersik and D. H. Zeuch, Creep and Creep Modeling of Three Domal Salts-A Comprehensive Update, SAND84-0568, Sandia National Laboratories, Albuquerque, NM 87185, p. 93.

9. A. N. Schofield, "Cambridge Geotechnical Centrifuge Operation," The Twentieth Rankine Lecture of the British Geotechnical Society. Geotechnique, 30 , No. 3, 1983, pp. 227-268.

10. G. 1. Pokrovsky and I. S. Fyodorov, Centrifuge Model Testing in the Construction Industry, 2 Vols, draft translation, Building Research Establishment Library. England, 1975.

11. G. H. Whiting, Strategic Petroleum Reserve Geological Site Characterization Report. West Hackberry Salt Dome, Sandia National Laboratories, SAND80-7131, October 1980.

12. D. S. Preece and J. T. Foley. Long-Term Performance Predictions for Strategic Petroleum Reserve (SPR) Salt Caverns, SAND83-2343, Sandia National Laboratories, Albuquerque, MM 87185, November 1984, p. 32.

13. R. R. Beasley and Samual $T$. Wallace, Strategic Petroleum Reserve (SPR) Cavern and Well Creep-Closure Tests, Sandia National Laboratories, SAND82-1765, April, 1984, p. 10. 
APPENDIX A

PLASTICINE :

EXPERIMENTAL PROCEDURES

A. INITIAL HANDLING

1. After removing from packing, place plasticine in an appropriate container (glass or metal) and heat to approximately $75^{\circ} \mathrm{C}$.

2. Rod the "Jiquefied" material to remove entrapped air.

3. Divide into appropriately sized units for future processing.

4. Cool to room temperature and store in aluminum foil or plastic wrap (if required).

B. COLORING OR CHANGING DENSITY

1. Heat plasticine to $75^{\circ} \mathrm{C}$.

2. Add predetermined amount of tempera paint powder to obtain desired color. Normal proportions: $50 \mathrm{gm}$ color to $1000 \mathrm{gm}$ of plasticine.

3. Mix the ingredients with a rod to obtain uniform consistency.

4. Record: a. The initial weight of the plasticine sample.

b. The weight of color added.

c. The weight of Barite added.

d. Final weight of the colored, weighted plasticine sample.

5. Divide into appropriately sized units for future processing.

6. Cool to room temperature and store in aluminum foil or plastic wrap (if required).

C. SHAPING TO SIZE

1. Heat material to be sized to $75^{\circ} \mathrm{C}$

2. Roll/pour the material to its initial dimensions. Go to Step C8 for casting process.

3. Cool to approximately $35^{\circ} \mathrm{C}$.

4. Roll/press the material to intermediate dimensions.

5. Cool to room temperature 
6. Let relax for a minimum of 24 hours.

7. Roll/press to final dimensions.

8. Freeze and store at a temperature of $0^{\circ} \mathrm{C}$ or less in aluminum foil or plastic wrap (if required).

9. Either water or silicone spray (mold release) may be used in these processes to eliminate sticking of the plasticine to the molding surface.

D. TEST FIXTURE ASSEMBLY AND PREPARATION

1. Assemble bottom and sides. Make sure that the curved base plate is aligned properly.

2. Place a layer of 0.005 inch teflon around the circumference of the mold (called teflon tape). A small quantity of contact cement may be required to hold the sheet against the sides of the mold.

3. Pour/roll/press a layer of plasticine into the base of the mold. The top surface of this layer should be flattened to provide a flat surface for building the remainder of the model.

E. MACHINING

1. Use machining techniques for soft materials.

2. Machine at $-20^{\circ} \mathrm{C}$ or below.

3. Store finished product at a temperature of $0^{\circ} \mathrm{C}$ or below in aluminum foil or plastic wrap.

F. ASSEMBLY

1. Lay up individual pieces of the frozen model as required.

2. Fill cavity(ies) with an appropriately shaped compressed salt plug (as required). Record all dimensions of the plug.

3. Install piping to cavities (as required).

4. Install all other instrumentation that is contained in the model. Measure and record instrumentation placement.

5. Place model into test fixture or, if appropriate, build directly in test fixture.

6. Freeze the model and store at a temperature of $0^{\circ} \mathrm{C}$ or less in the test fixture. Cover with aluminum foil, plastic wrap or with the top of the fixture. 
G. PRETEST

1. Warm the model to the appropriate test temperature over a period of at least 24 hours.

2. Using appropriate mechanical measurements, measure and record the position of the surface of the model along predetermined scribed axis(es) (as required).

3. Attach all instrumentation to the model that can be attached before installation on the centrifuge. Measure and record positions.

4. Run all necessary instrumentation checks and make corrections/replacements/ calibrations that are required. Record all changes and all calibrations.

5. Check all "on-board" instrumentation and make corrections/replacements/calibrations that are required. Record all changes and all calibrations.

6. Using water at the same temperature of the model (the test temperature), dissolve the salt plugs from the cavity(ies) in the model. Wash the cavity out at least two times with water. Then wash out the cavity with Isopropyl Alcohol (2-Propanol). Drain cavity and allow the alcohol to evaporate. Record time.

7. Measure the quantity of liquid required to fill the cavity using a graduated cylinder to measure the quentity of liquid required to fill the cavity to a specified height.

8. Check surface position measurements to determine if they are still correct (as required). Record any variations from original measurements. Record time.

9. Fill all cavities with Methenol Alcohol.

10. Complete the mounting of the model and connecting/calibrating of the on-board instrumentation to the model. Connect "inlet" pipes to "riser" pipes with 910 cynoacrylate (epoxy). The connector is a $1 / 4$ inch Swaglock Nylon Fitting (1/4"X 1/4" 90$)$ with the threads turned down on one end. The stand pipe is $1 / 4$ inch Impolene Tubing (Imperial Eastman 44-pp-1/4).

11. Mount the model on the centrifuge. Fill stand pipes to cavities with desired liquid (as required). Do as quickly as possible within the confines of proper experimental procedures. Record time. 
H. TESTING PROCEDURES

1. Preheat (cool) the centrifuge room to the appropriate temperature.

2. Run final checks of all instrumentation.

3. Check centrifuge for safety. Follow site operation/safety rules.

4. Conduct test.

5. Record test times and acceleration history.

I. POST TEST PROCEDURES

1. Remove the model from the centrifuge as quickly as possible. Place in a vertical position. Record time.

2. Measure the final volume of cavities by filling with the desired liquid. Measure input liquids using a graduated cylinder.

3. Freeze the model to $0^{\circ} \mathrm{C}$ or below as quickly as possible. Record time this process is started (and finished).

4. Measure and record surface positions along the scribed axis(es) (as required)

5. Section the model (as required). Photograph the sections with and without a glass overlay scale (grid). 
APPENDIX B

SALT PLUGS:

EXPERIMENTAL PROCEDURES

A. MOLDS

1. Construct a "breakaway" mold(s) from pyrex glass or metal for the salt plugs. Inside dimensions should correspond to the inside dimensions of the cavity to be filled.

2. Spray the inside of the mold with teflon spray (dry mold release) to prepare for the molding process.

B. SALT PREPARATION

1. Obtain reagent grade $\mathrm{NaCl}$.

2. Using a large mortar \& pestle (\#7) pulverize the NaCl to the consistency of fine sand.

3. Mix pulverized salt with a minimum of water to create a "damp" (but not overly wet) dough like mixture.

4. Pack mixture into prepared mold. Tamp carefully--not too tight. Heat to $200^{\circ} \mathrm{C}$ for 4 or 5 hours. Leave overnight at $70^{\circ} \mathrm{C}$. Plugs can now be stored for future use.

5. Remove specimen from mold by applying a slight pressure.

6. If plug is to be machined to size, let specimen cool for at least. 1 hour after step 4 . Use machining techniques suitable for granular materials. The plug should be machined 0.100 inch undersize on the length and 0.050 undersize on the diameter for the coating described below.

C. PREPARING THE STAND PIPE

1. Use a rigid plastic pipe (Thermo tube $-7 / 16$ inch OD with approximately $1 / 32$ inch wall).

2. Buff one end slightly using a fine file.

3. Coat the buffed section with Dow Corning 1204 Primer. 
D. COATING THE SALT PLUGS

1. Make up an appropriate batch of SYLGARD 170 (equal weights of A \& B). Let stand for a minimum of 1 hour to de-air. A vacuum may be pulled on the compound to speed this process.

2. Heat the salt plug to $200^{\circ} \mathrm{C}$.

3. Using a paint brush, paint the bottom of the plug. Being careful to cover the corner, extend the SYLGARD up the sides of the plug. The compound should be curing immediately.

4. Invert the plug so that the "top" is pointing up. Continue painting up the sides and around the corner.

5. Position inlet tube, buffed section down, in its appropriate position (usually the center of the plug), and paint around it. Extend the paint up the tube approximately $1 / 2$ inch and over to the previously painted section.

6. Let dry for approximately 3 minutes.

7. Paint the cured SYLGARD with Dow Corning 1204 primer (with an "acid" brush).

8. Let dry for 1 or 2 hours at room temperature.

E. PLACEMENT IN MODELS

1. Place SYLGARD in the bottom of the cavity.

2. Insert the plastic coated salt plug into the cavity.

3. Backfill the space between the plug and the cavity (to its top) with SYLGARD. As air rises to the top, continue to backfill the cavity to its top (approximately 30 minutes).

4. Let stand for a minimum of 24 hours at room temperature to cure. 
C MAKE COORDINATES AXISMMETRIC ABOUT R AXIS

C

DO $100 \quad K=1,2$

$\operatorname{RSHFT}(K)=R(K, 1)-(\operatorname{MINR}(K)+\operatorname{MAXR}(K)) / 2.0$

RTRANS $=\mathrm{R}(K, 1)$

DO $100 \quad I=1, \operatorname{NUM}(K)$

$R(K, I)=R(K, I)-R T R A N S$

$\mathrm{C}$

100 CONTINUE

C SHIFT THE LOOP SO $R(K, 1)$ IS CENTERED

C

Do $140 \mathrm{~K}=1,2$

DO $130 \quad l=2$, NUM(K)

IF (RSHFT(K).LT.0.0) GO TO 110

I $E N D=N U M(K)-1$

IF (IEND.LT . 5.AND . ABS $(R(K, I)) \cdot G T \cdot \operatorname{RSHFT}(K))$ GO TO 120

$R(K, I)=R(K, I)+R S H F T(K)$

GO TO 120

110 CONTINUE

IF (I LT . 5.AND . ABS (RSHFT (K)) . GT.R(K,I )) GO TO 120

120

$R(K, I)=R(K, I)+R S H F T(K)$

130 CONTINUE

C

CONTINUE

$\mathrm{C}$

COMPENSATE FOR CUT BEING OFF CENTER

$\mathrm{C}$

DO $145 \quad K=1,2$

DO $145 \mathrm{I}=1, \mathrm{NUN}(\mathrm{K})$

IF (ABS $(R(K, I))$.LT.0.5) Go TO 145

$\operatorname{SGN}=R(K, I) / \operatorname{ABS}(R(K, I))$

$R(K, I)=\operatorname{SQRT}(\operatorname{OFST}(K) * * 2+R(K, 1) * * 2) * S G N$

C

145 CONTINUE

$\mathrm{C}$

PLACE POINTS WITH NEGATIVE R INTO SEPARATE LISTS

$\mathrm{C}$

Do $160 \mathrm{~K}=1,2$

I NUM $=\mathrm{NUM}(\mathrm{K})$

I TEST $=0$

DO $160 \mathrm{I}=1$, INUM

IF (R(K, I ).GE.0) GO TO 160

IF (ITEST .EQ. 1) GO TO 150

I TEST $=1$

$\operatorname{NUM}(K)=I-1$

$\mathrm{KK}=\mathrm{K}+2$

I I $=1$

$\operatorname{NUM}(\mathrm{KK})=\mathrm{INUM}-\mathrm{NUM}(\mathrm{K})$

150 CONTINUE

$\mathrm{R}(\mathrm{KK}, \mathrm{I} \mathrm{I})=\mathrm{R}(\mathrm{K}, \mathrm{I})$

$Z(K K, I I)=Z(K, I)$

$\mathrm{I} I=\mathrm{I} I+1$

$\mathrm{C}$

160 CONTINUE

C GENERATE NODE LIST FOR EACH STRING 


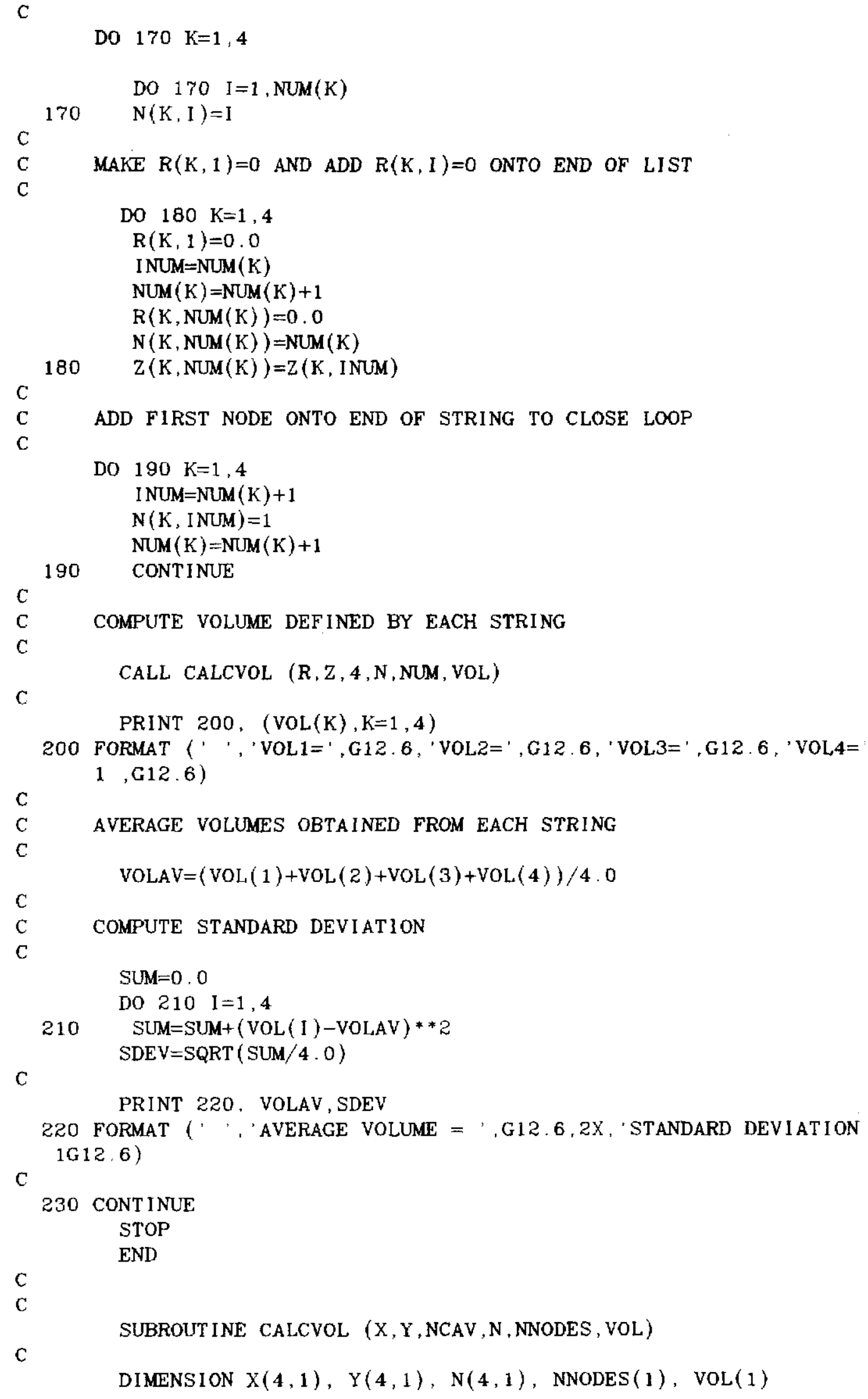

$\mathrm{C}$

PRINT 220, VOLAV, SDEV 
DIMENSION A(4), XBAR(4), YBAR(4)

DATA PI $/ 3,141592654 /$

$\mathrm{C}$

C CALCULATE CAVITY AREAS

C

DO $20 \mathrm{~K}=1, \mathrm{NCAV}$

$\mathrm{SUM}=\mathrm{X}(\mathrm{K}, \mathrm{N}(\mathrm{K}, 1)) * \mathrm{Y}(\mathrm{K}, \mathrm{N}(\mathrm{K}, 1))$

$\operatorname{MAXN}=\operatorname{NNODES}(K)-1$

DO $10 \mathrm{~J}=1, \mathrm{MAXN}$

$\mathrm{I}=\mathrm{J}+1$

10

SUM $=\operatorname{SUM}+(\mathrm{Y}(\mathrm{K}, \mathrm{N}(\mathrm{K}, \mathrm{I}))-\mathrm{Y}(\mathrm{K}, \mathrm{N}(\mathrm{K}, \mathrm{J})))^{*}(\mathrm{X}(\mathrm{K}, \mathrm{N}(\mathrm{K}, \mathrm{I}))+\mathrm{X}(\mathrm{K}, \mathrm{N}(\mathrm{K}, \mathrm{J})))$ $\operatorname{SUM}=\operatorname{SUM}-Y(K, N(K, \operatorname{NNODES}(K))) * X(K, N(K, \operatorname{NNODES}(K)))$

$\mathrm{C}$ $\mathrm{A}(\mathrm{K})=\mathrm{ABS}(\mathrm{SUM} / 2.0)$

C

C

CALCULATE XBAR

INDEX $=1$

CALL CNTRD (X, Y, INDEX, N, NNODES, $K, A$, XBAR)

C

$\mathrm{C}$

$\mathrm{C}$

CALCULATE YBAR

INDEX $=2$

CALL CNTRD ( $Y, X, I N D E X, N$, NNODES $, K, A, Y B A R$ )

$\mathrm{C}$

$\mathrm{C}$

$\mathrm{C}$

CALCULATE CAVITY VOLUMES

20

$\operatorname{XBAR}(K)=\operatorname{ABS}(\operatorname{XBAR}(K))$

$\operatorname{VOL}(\mathrm{K})=2 * \mathrm{PI} * \mathrm{XBAR}(\mathrm{K}) * \mathrm{~A}(\mathrm{~K})$

RETURN

END

$\mathrm{C}$

$\mathrm{C}$

$\mathrm{C}$

SUBROUT INE CNTRD (U, V, INDEX, N, NNODES , K, A, CENTER)

DIMENSION $U(4,1), V(4,1), N(4,1), \operatorname{NNODES}(1), A(1), \operatorname{CENTER}(1)$

$\mathrm{SUM}=\mathrm{V}(\mathrm{K}, \mathrm{N}(\mathrm{K}, 1)) / 8^{*}\left(\mathrm{U}(\mathrm{K}, \mathrm{N}(\mathrm{K}, 1)) * * 2+.33333333^{*} \mathrm{U}(\mathrm{K}, \mathrm{N}(\mathrm{K}, 1))^{* * 2}\right)$

$\operatorname{MAXN}=\operatorname{NNODES}(\mathrm{K})-1$

DO $10 \mathrm{~J}=1, \operatorname{MAXN}$

$\mathrm{I}=\mathrm{J}+1$

$\mathrm{SUM}=\mathrm{SUM}+(\mathrm{V}(\mathrm{K}, \mathrm{N}(\mathrm{K}, \mathrm{I}))-\mathrm{V}(\mathrm{K}, \mathrm{N}(\mathrm{K}, \mathrm{J}))) / 8.0 *((\mathrm{U}(\mathrm{K}, \mathrm{N}(\mathrm{K}, \mathrm{I}))+$

$\left.1 \mathrm{U}(\mathrm{K}, \mathrm{N}(\mathrm{K}, \mathrm{J})))^{* *} \mathrm{Z}+1.333333^{*}(\mathrm{U}(\mathrm{K}, \mathrm{N}(\mathrm{K}, \mathrm{I}))-\mathrm{U}(\mathrm{K}, \mathrm{N}(\mathrm{K}, \mathrm{J})))^{* * 2}\right)$

10 CONTINUE

$N S H=N N O D E S(K)$

$\mathrm{SUM}=\mathrm{SUM}-\mathrm{V}(\mathrm{K}, \mathrm{N}(\mathrm{K}, \mathrm{NSH})) / 8.0^{*}\left(\mathrm{U}(\mathrm{K}, \mathrm{N}(\mathrm{K}, \mathrm{NSH}))^{* * 2+}\right.$

$10.333333 * U(K, N(K, N S H)) * * 2)$

$\operatorname{CENTER}(K)=1.0 / \mathrm{A}(\mathrm{K}) *$ SUM

IF (INDEX.EQ. 1) CENTER(K)=-CENTER(K)

RETURN

END

$\mathrm{C}$

$\mathrm{C}$

$\mathrm{C}$

SUBROUTINE OPEN (FILEID, IUNIT, IOP, IERROR) 


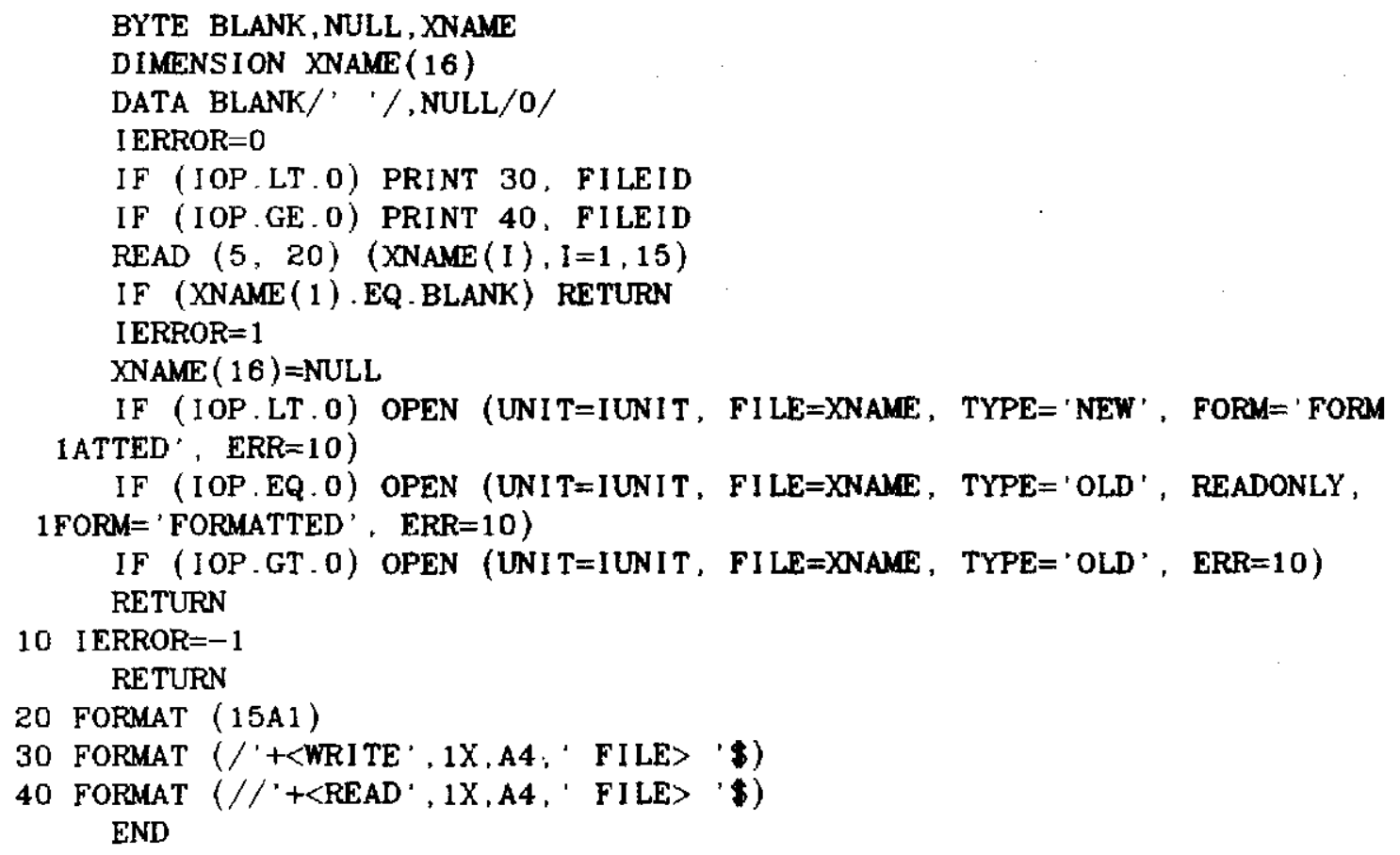


APPENDIX D

\author{
Finite Element Simulations \\ of the Cavity Creep Closure
}

FINITE ELEMENT SIMULATION

The finite element program [D-1] employed in this study has been used to predict creep closure of underground nuclear waste storage drifts [D-2], [D-3]. It was also used to study laboratory triaxial creep experiments [D-4] and to calculate the performance of petroleun storage cavities in rock salt [D-5], [D-6] and [D-7]. The finite element model of the fluid-filled cavity in plasticine is shown in Figure D-1. The boundary displacement constraints are represented by rollers where displacement is allowed parallel to the roller but not perpendicular to it. The model loading consists of body forces, a surcharge on top of the model and fluid pressure insjde the cavity. All of these are scaled with acceleration. A comparison between the finite element calculations and the centrifuge experiments is shown in Figure D-2 where cavity percent volume loss is plotted against acceleration. This figure shows the calculated percent volume loss, with fluid head from top of riser tube, increasing linearly between $100 \mathrm{~g}$ and $150 \mathrm{~g}$. Figure D-Z also shows good comparison between experiment and calculation at $100 \mathrm{~g}$ and $125 \mathrm{~g}$ but a significant discrepancy at $150 \mathrm{~g}$. The probable cause for this discrepancy is loss of some fluid from the riser tube during the experiment. Post-test observation of this model showed a small rupture where the riser tube connects to the cavity. Another possible cause of this discrepancy, which was investigated and ruled out was the triggering of another creep mechanism in the plasticine at the higher stress level. This cause is not likely since the calculated value of maximum creep driving stress is within the range of the stresses seen in the unconfined compression tests (Figure 2). Figure D-2 also shows another set of $f$ inite element calculations performed as mentioned previously except the fluid level was assumed at the top of the cavity instead of at the top of the riser tube. This set of calculations gives significantly greater closure at all three acceleration levels and comes much closer to the 


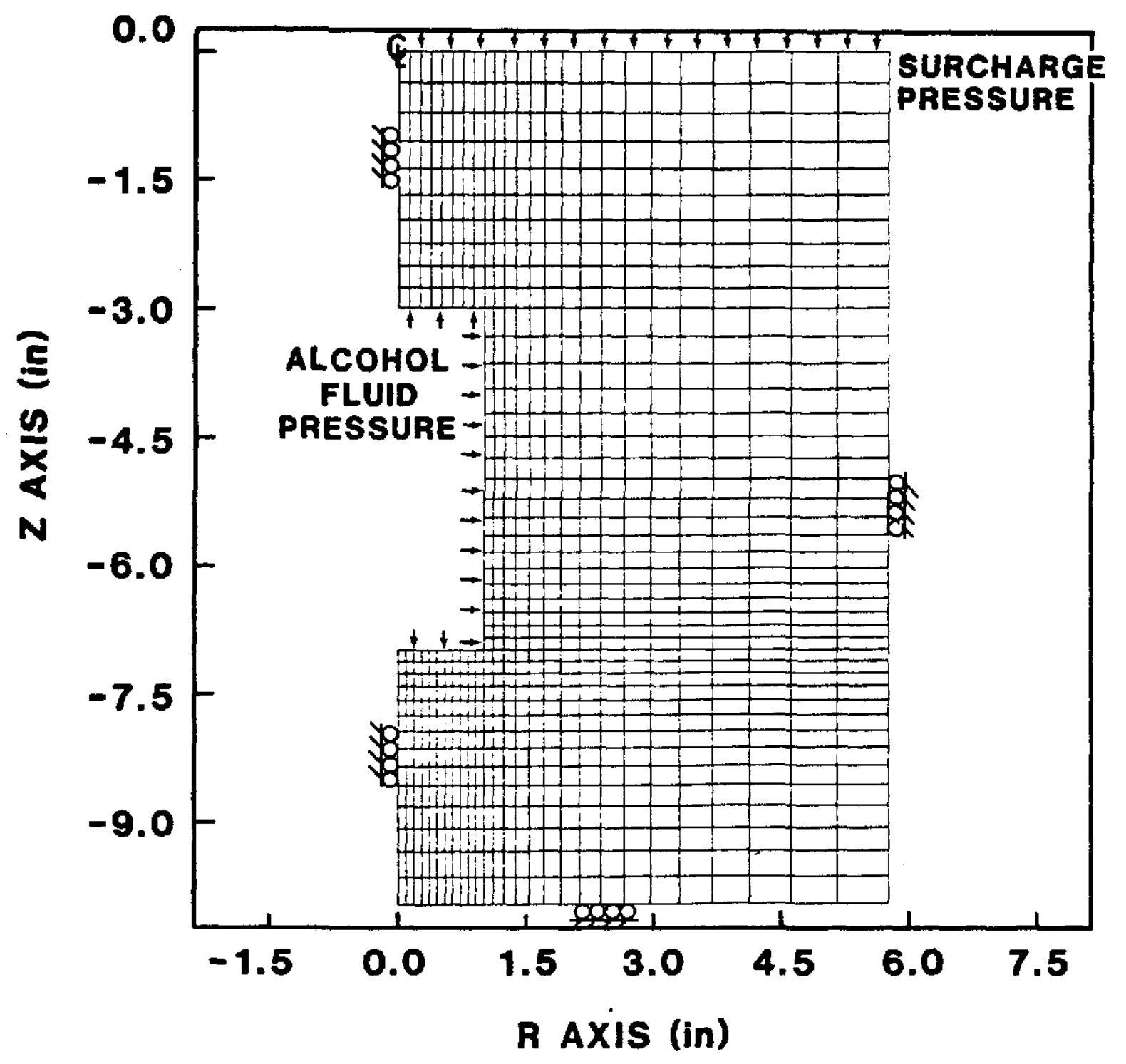

Figure D-1: Axisymmetric Finite Element Model of Single Cavity Experiments 


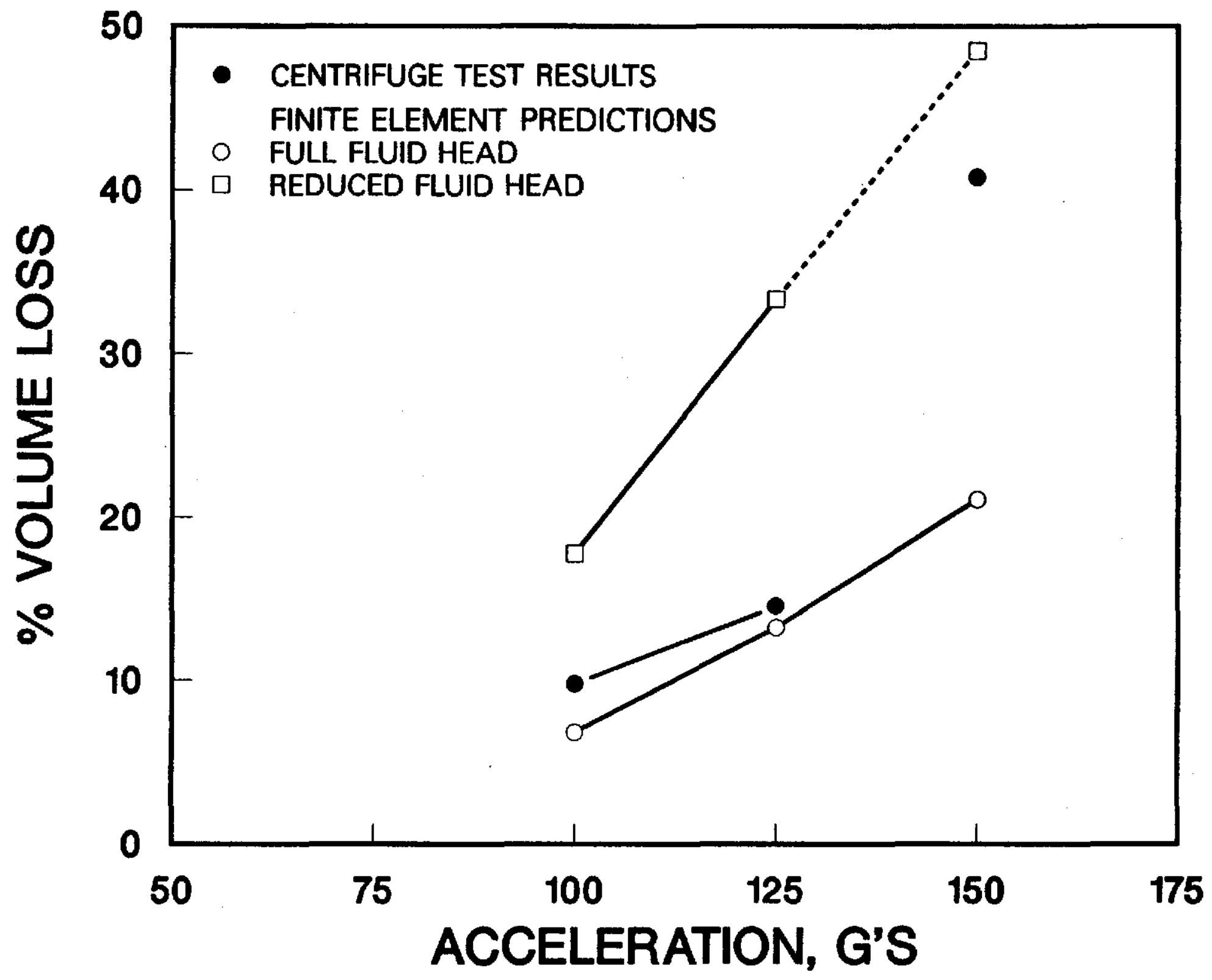

Figure D-2: Comparison of Experimental and Finite Element Results 
experimental closure at $150 \mathrm{~g}$. The $150 \mathrm{~g}$ centrifuge experiment and the reduced fluid level finite element calculations show the influence of cavity fluid pressure on creep closure. Small reductions in head and, consequently pressure can result in significant increases in cavity volume loss.

\section{REFERENCES}

D-1 S. W. Key, C. M. Stone, and R. D. Krieg, A Solution Strategy for the Quasi-Static Large Deformation, Inelastic Response of Axisymetric Solids, presented at U.S. European Workshop Nonlinear Finite Element Analysis in Structural Mechanics, Ruhr-Universitat; Bochum, West Germany, 1980 .

D-2 H. S. Morgan, R. D. Krieg, and R. V. Matalucci, Comparative Analysis of Nine Structural Codes Used in the Second WIPP Benchmark Problem, Sandia National Laboratories, SAND81-1389, 1981.

D-3 J. D. Miller, C. M. Stone, and L. J. Branstetter, Reference Calculations for Underground Rooms of the WIPP. Sandia National Laboratories, SANDB2-1176, 1982 .

D-4 L. J. Branstetter and D. S. Preece, "Numerical Studies of Laboratory Triaxial Creep Tests." Proceedings of 24th Symposium on Rock Mechanics, Texas A\&M University, 1983, pp. 37-51.

D-5 D. S. Preece and C. M. Stone, "Verification of Finite Element Methods Used to Predict Creep Closure of Leached Salt Caverns." Proceedings of 23rd Symposium on Rock Mechanics, Berkeley, California, 1982, pp. 655-663.

D-6 D. S. Preece and W. R. Wawersik, "Leached Salt Cavern Design Using a Fracture Criterion for Rock Salt," Proceedings of 25th Symposium on Rock Mechanics, Northwestern University, 1984, pp. 556-565.

D-7 D. S. Preece and J. T. Foley, "Finite Element Analysis of Salt Caverns Employed in the Strategic Petroleum Reserve with Comparison to Field Data," In Situ, Volume 8, Number 3, 1984, pp. 233-266. 


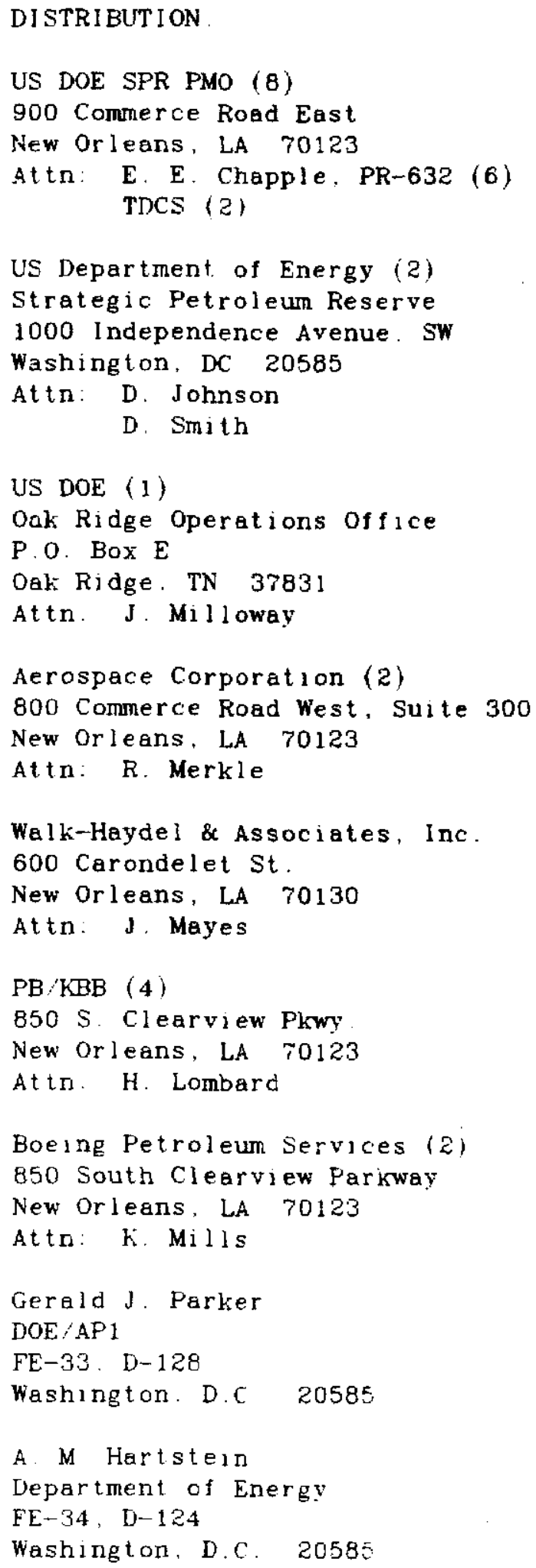




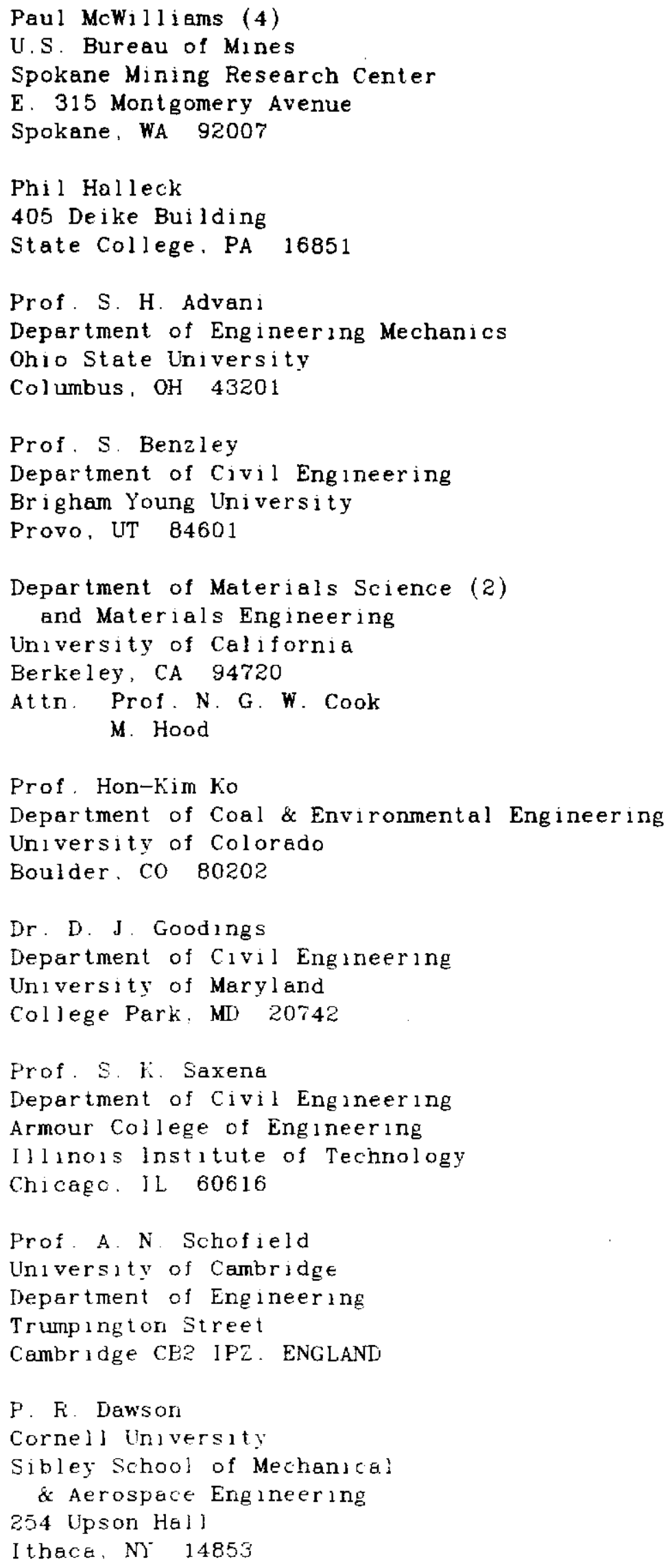




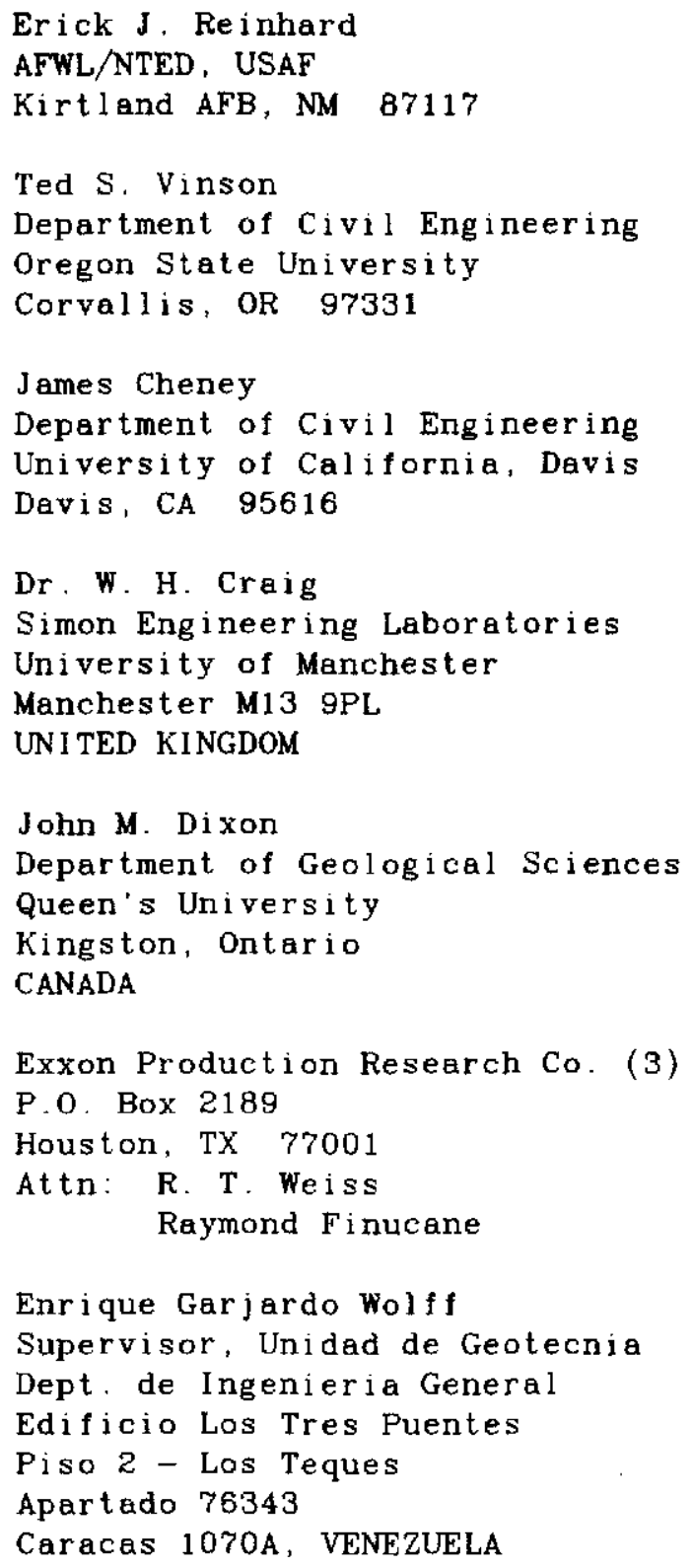

$\begin{array}{ll}1510 & \text { J. W. Nunziato } \\ 1512 & \text { J. C. Cummings } \\ 1512 & \text { A. J. Russo } \\ 1520 & \text { D. J. McCloskey } \\ 1521 & \text { R. D. Krieg } \\ 1521 & \text { D. S. Preece (10) } \\ 1522 & \text { R. C. Reuter } \\ 1522 & \text { J. T. Foley (10) } \\ 1530 & \text { L. W. Davison } \\ 1540 & \text { W. C. Luth } \\ 1542 & \text { W. R. Wawersik } \\ 1821 & \text { N. E. Brown }\end{array}$




$\begin{array}{ll}3141 & \text { C. Ostrander (5) } \\ 3144 & \text { W. R. Roose (5) } \\ 3151 & \text { W. L. Garner (3) } \\ 3154-3 & \text { C. H. Dalin (28) } \\ & \text { DOE/TIC (Unl imited Release) } \\ 6200 & \text { V. L. Dugan } \\ 6250 & \text { B. W. Marshall } \\ 6256 & \text { D. Engi } \\ 6256 & \text { H. J. Sutherland (30) } \\ 6257 & \text { J. K. Linn (10) } \\ 6257 & \text { R. R. Beasley } \\ 6257 & \text { J. L. Todd } \\ 6330 & \text { W. D. Weart } \\ 8424 & \text { M. A. Pound }\end{array}$

